\title{
Enterococcus faecalis utilizes maltose by connecting two incompatible metabolic routes via a novel maltose-6'-phosphate phosphatase (MapP)
}

\author{
Abdelhamid Mokhtari ${ }^{1,2,3, \S}$, Víctor S. Blancato ${ }^{4, \S}$, Guillermo Repizo ${ }^{4}$, Céline Henry ${ }^{1,2}$, \\ Andreas Pikis $^{5}$, Alexa Bourand ${ }^{1,2,6}$, María de Fátima Álvarez ${ }^{7}$, Stefan Immel ${ }^{8}$, Aicha \\ Mechakra-Maza $^{3}$, Axel Hartke ${ }^{9}$, John Thompson ${ }^{10}$, Christian Magni ${ }^{4}$, and Josef \\ Deutscher ${ }^{1,2,6, *}$ \\ ${ }^{1}$ INRA, Microbiologie de l'alimentation au service de la santé humaine (MICALIS), UMR1319, \\ F-78350 Jouy en Josas, France \\ ${ }^{2}$ AgroParisTech, MICALIS, UMR1319, F-78350 Jouy en Josas, France \\ ${ }^{3}$ Laboratory of Environmental Biology, Department of Biochemistry-Microbiology, Faculty of \\ Natural Science and Life, University Mentouri, 25017 Constantine, Algeria \\ ${ }^{4}$ Instituto de Biología Molecular y Celular de Rosario (IBR-CONICET) and Departamento de \\ Microbiología, Facultad de Ciencias Bioquímicas y Farmacéuticas, Universidad Nacional de \\ Rosario, (S2002LRK) Rosario, Argentina \\ ${ }^{5}$ Center for Drug Evaluation and Research, Food and Drug Administration, Silver Spring, \\ Maryland 20993, USA \\ ${ }^{6}$ CNRS, MICALIS, SNC9130, F-78350 Jouy-en-Josas, France \\ ${ }^{7}$ Instituto Superior de Investigaciones Biológicas (INSIBIO-UNT-CONICET) y Departamento de \\ Biología del Desarrollo, Facultad de Bioquímica, Química y Farmacia, Universidad Nacional de \\ Tucumán, (4000) Tucumán, Argentina \\ ${ }^{8}$ Institut für Organische Chemie, Technische Universität Darmstadt, D-64287 Darmstadt, \\ Germany \\ ${ }^{9}$ Université de Caen Basse-Normandie, EA4655, U2RM Stress/Virulence, F-14032 CAEN, \\ France \\ ${ }^{10}$ Microbial Biochemistry and Genetics Unit, Laboratory of Cell and Developmental Biology, \\ NIDCR, National Institutes of Health, Bethesda, MD 20892, USA
}

\section{Summary}

Similar to Bacillus subtilis, Enterococcus faecalis transports and phosphorylates maltose via a phosphoenolpyruvate (PEP):maltose phosphotransferase system (PTS). The maltose-specific PTS permease is encoded by the malT gene. However, E. faecalis lacks a malA gene encoding a 6phospho-a-glucosidase which in B. subtilis hydrolyses maltose-6'-P into glucose and glucose-6-P. Instead, an operon encoding a maltose phosphorylase (MalP), a phosphoglucomutase and a mutarotase starts upstream from malT. MalP was suggested to split maltose-6-P into glucose-1-P and glucose-6-P. However, purified MalP phosphorolyses maltose but not maltose-6'-P. We discovered that the gene downstream from malT encodes a novel enzyme (MapP) that dephosphorylates maltose-6'-P formed by the PTS. The resulting intracellular maltose is cleaved

*For correspondence. Josef.Deutscher@ grignon.inra.fr; Tel. (+33) 1308154 47; Fax (+33) 130815457.

$\S$ These two authors equally contributed to this work. 
by MalP into glucose and glucose-1-P. Slow uptake of maltose probably via a maltodextrin ABC transporter allows poor growth for the mapP but not the malPmutant. Synthesis of MapP in a $B$. subtilis mutant accumulating maltose-6'-P restored growth on maltose. MapP catalyzes the dephosphorylation of intracellular maltose-6'-P, and the resulting maltose is converted by the $B$. subtilis maltose phosphorylase into glucose and glucose-1-P. MapP therefore connects PTSmediated maltose uptake to maltose phosphorylase-catalyzed metabolism. Dephosphorylation assays with a wide variety of phospho-substrates revealed that MapP preferably dephosphorylates disaccharides containing an O-a-glycosyl linkage.

\section{Keywords}

Enterococcus faecalis; phosphotransferase system; maltose transport; maltose-6'-P phosphatase; maltose phosphorylase

\section{Introduction}

The breakdown of the two starch-forming polysaccharides amylose and amylopectin, which contain glucose molecules connected by a $(1 \rightarrow 4)$ glycosidic bonds, by the enzyme aamylase leads to the formation of the disaccharide maltose (4-O-a-D-glucopyranosyl-Dglucopyranose). Starch is produced by all green plants as an energy store and is therefore an abundant carbon source for bacteria. Plants synthesize a-amylases mainly during maturation of their fruits and germination of their seeds. a-Amylase activity is also found in the saliva of humans and animals. In addition, many bacteria possess an a-amylase able to degrade starch. Escherichia coli K12 and many other enterobacteria have the capacity to utilize maltose and maltodextrin (Dippel and Boos, 2005), which results from incomplete hydrolysis of starch from various plant origins. Depending upon the degree of hydrolysis maltodextrin contains variable amounts of glucose, maltose, maltotriose and higher maltose oligosaccharides. Most enterobacteria take up maltose and maltodextrins via an ABC transport system composed of the maltose binding protein MalE, two transmembrane proteins MalF and MalG and the ATP binding protein MalK, which provides the energy for maltose uptake by hydrolyzing ATP. The two membrane proteins and the nucleotide binding protein form a MalF/MalG/(MalK) 2 complex, the structure of which has been solved for the E. coli proteins (Daus et al., 2009; Gould and Shilton, 2010). Only maltose carried by the maltose binding protein MalE is recognized by the integral membrane proteins and transported into the cell.

Firmicutes can transport maltose by at least four different systems. Firstly, several lactobacilli, such as Lactobacillus salivarius, Lactobacillus fermentum, Lactobacillus buchneri and Lactobacillus reuteri use the MalY protein for maltose uptake. This LacY type ion co-transporting maltose permease was first described in the a-proteobacterium Caulobacter crescentus (Lohmiller et al., 2008). Homologous transporters are also present in the $\beta$-proteobacterium Neisseria meningitidis and in several verrumicrobiae, such as Opitutus terrae or Pedosphaera parvula. In these organisms the permease gene is located in an operon together with the genes encoding homologues of maltose phosphorylase, phosphoglucomutase and sometimes also aldose 1-epimerase (A. Mazé and J. Deutscher, unpublished observation). It is therefore likely that maltose taken up by MalY is phosphorolyzed by MalP to glucose and glucose-1-P, with the latter being converted into glucose-6-P by the enzyme phosphoglucomutase.

Secondly, similar to enterobacteria, some firmicutes use a single ABC transporter for the efficient uptake of maltose and maltodextrins. This has been reported for Listeria monocytogenes (Gopal et al., 2010), Lactobacillus casei (Monedero et al., 2008) and 
Lactococcus lactis (Andersson and Rådström, 2002). The genes encoding the extracellular enzymes required for the degradation of starch are either included in the malEFG operon or sometimes located upstream from it and oriented in the opposite direction, as is the case for L. lactis (Andersson and Rådström, 2002). Maltose taken up by the ABC transporter is cleaved by maltose phosphorylase (MalP or Map) into glucose-1-P and glucose, which are both converted into glucose-6-P by the enzymes phosphoglucomutase and glucokinase, respectively. In addition to malP a gene encoding the enzyme phosphoglucomutase is therefore frequently associated with the malEFGK operon (Gopal et al., 2010; Monedero et al., 2008).

Several other firmicutes also contain an $\mathrm{ABC}$ transporter, which, however, preferably transports dextrins. Maltose is efficiently transported by these ABC transporters only when present at high concentrations. Such systems have been described for Bacillus subtilis (Schönert et al., 2006) (Fig. 1), Enterococcus faecalis (Le Breton et al., 2005) and Streptococcus pyogenes (Shelburne III et al., 2008). These bacteria use an inducible phosphoenolpyruvate (PEP):carbohydrate phosphotransferase system (PTS) as high affinity transporter for maltose.

A functional PTS is usually composed of five proteins or domains, four of which form a phosphorylation cascade. Phosphorylation of the PTS components occurs at His or Cys residues. Enzyme I autophosphorylates at the expense of PEP, and transfers the phosphoryl group to His-15 in HPr. EI and HPr are the common PTS components usually functioning with all sugar-specific PTS of an organism. P His-HPr phosphorylates one of several sugarspecific EIIAs present in a bacterial cell. An EIIB with the same sugar specificity receives the phosphoryl group from EIIA and transfers it to the carbohydrate bound to EIIC, the integral membrane component of the PTS. The phosphorylated carbohydrate is subsequently released into the cytoplasm. Transport and phosphorylation by PTS components are therefore tightly coupled.

Regarding the transport of maltose, two types of PTS can be distinguished. One uses an EIICB $^{\mathrm{Mal}}$ (called MalP or GlvC), which in E. coli functions together with the glucosespecific EIIA (Pikis et al., 2006), whereas in B. subtilis the EIIA Glc domain of PtsG was not required for maltose uptake (Schönert et al., 2006). In addition to the gene encoding the PTS permease the operon contains a gene coding for a maltose-6'-P hydrolase (MalA, also called GlvA), an NAD ${ }^{+} \mathrm{Mn}^{2+}$-dependent 6-P-a-glucosidase (EC 3.2.1.122) (Rajan et al., 2004; Thompson et al., 1998; Yip et al., 2007) that is assigned to the unique Family 4 of the glycoside hydrolase superfamily (Cantarel et al., 2009; Hall et al., 2009) (Fig. 1).

Maltose-6'-P formed during PTS-catalyzed transport is hydrolyzed to glucose-6-phosphate and glucose by maltose-6'-P hydrolase. [The 6'-P notation indicates phosphorylation of the C6 hydroxyl group of the non-reducing glucose moiety of the disaccharide]. Such systems have been reported for Fusobacterium mortiferum (Robrish et al., 1994; Thompson et al., 1995), Clostridium acetobutylicum (Thompson et al., 2004) and B. subtilis (Schönert et al., 2006). A BLAST search revealed that identical operons are present in many other bacilli, geobacilli, clostridia, fusobacteria, leptotrichiae, etc. In addition, putative maltose PTS operons composed of genes coding for an EIICB and a maltose-6'-P hydrolase are found in many proteobacteria, such as serratiae, pectobacteria, cronobacter and a few E. coli strains. Some of these organisms also contain a gene in the operon encoding a distinct EIIA component.

In contrast to the above bacteria, E. faecalis JH2-2 (Le Breton et al., 2005), Streptococcus mutans (Webb et al., 2007) S. pyogenes (Shelburne III et al., 2008) and Streptococcus pneumoniae (Bidossi et al., 2012) transport maltose via an EIICBA protein of the glucose subfamily of PTS transporters (MalT). In most enterococci and streptococci malT 
(EFT41760 in E. faecalis JH2-2) is followed by a gene encoding a protein of unknown function (Fig. 1). In contrast with $B$. subtilis, cells of E. faecalis and streptococci lack maltose-6'-P hydrolase, which raises questions pertaining to the route for dissimilation of maltose-6'-P in these organisms. Trehalose-6'-P formed during PTS-catalyzed transport by L. lactis is hydrolyzed by the trehalose-6'-P phosphorylase (which exhibits significant similarity to maltose phosphorylase) into glucose-1-P and glucose-6-P (Andersson et al., 2001). It was therefore proposed that in E. faecalis JH2-2 maltose-6'-P might be similarly hydrolyzed by maltose phosphorylase (MalP, sometimes also called Map) (Le Breton et al., 2005), the gene of which is divergently oriented next to the transporter gene malT(Fig. 1). Indeed, growth of $E$. faecalis on maltose leads to the induction of the mal operon encoding maltose phosphorylase, phosphoglucomutase and mutarotase. However, trehalose is a symmetric molecule composed of two non-reducing glucose moieties connected by an $a(1 \rightarrow 1)$ glycosidic bond, and phosphorolysis of the phosphorylated disaccharide yields glucose-1-P and glucose-6-P (Andersson et al., 2001). In contrast, maltose contains an $a(1 \rightarrow 4)$ glycosyl linkage, and phosphorolysis of maltose-6'-P should predictably yield glucose-1,6-bisphosphate and glucose. Alternatively, phosphorolytic attachment of the phosphoryl group to the reducing glucose moiety would generate glucose-6-P and glucose-4-P. However, glucose-4-P is not a known metabolite, and glucose-1,6-bisphosphate serves only as a requisite cofactor in phosphoglucomutase catalysis. Finally, it was conceivable that maltose might not be phosphorylated during PTS transport similar to the PTS-catalyzed uptake of fucosyl-a $(1 \rightarrow 3)$-N-acetylglucosamine by L. casei (Rodríguez-Díaz et al., 2012), or less likely, that during translocation the disaccharide was phosphorylated at C6 of the reducing glucose moiety. In light of these uncertainties we have conducted an indepth study, utilizing genetic and biochemical methods, to elucidate the pathway for the metabolism of this disaccharide in E. faecalis.

\section{Results}

\section{MalP exhibits maltose phosphorylase but not maltose-6'-P phosphorylase activity}

Strain JH2-2 used in this study is identical to strain TX4000 (Nallapareddy et al., 2002), the genome of which has recently been determined (see NCBI WebSite: http:// www.ncbi.nlm.nih.gov/genome/808?project_id=181499). In order to faciltate tracking of the genes described in this study we also mention the gene designations of TX4000 (EFT....). The operon located upstream from the previously identified $E$. faecalis JH2-2 PTS permease gene malT (EFT41760) (Le Breton et al., 2005) is oriented in the opposite direction (Fig. 1) and contains four genes. The first gene (EFT41759) encodes a protein exhibiting more than $55 \%$ sequence identity to maltose phosphorylase from Lactobacillus casei (Monedero et al., 2008) and other firmicutes. This operon seems to play an important role in maltose metabolism in $E$. faecalis because biofilm formation by maltose-grown cells was strongly affected when it was deleted (Creti et al., 2006). In order to test whether EFT41759 was indeed capable of cleaving maltose-6'-P formed during PTS-catalyzed maltose transport, as suggested in a previous study (Le Breton et al., 2005), we cloned the gene into a His-tag expression vector, purified the protein as described in Experimental procedures and carried out spectrophotometric activity assays. We first tested whether the enzyme was able to phosphorolyse maltose, which would lead to the formation of glucose-1-P and glucose. The formation of glucose was detected by using a coupled NADP-requiring spectrophotometric assay as described in Experimental procedures. The formation of NADPH, which in our assay system is directly related to maltose phosphorylase activity, was followed by measuring the change in absorption at $340 \mathrm{~nm}$. A rapid increase in absorption at $340 \mathrm{~nm}$ was observed when maltose was used as substrate (data not shown). However, increase in $\mathrm{A}_{340 \mathrm{~nm}}$ was negligible when maltose was replaced with maltose-6'-P. Nevertheless, the possible products of the two presumed modes of the maltose-6'-P phosphorolysis reaction 
should have been detected with our assay: Transferring the phosphoryl group to the first glucose moiety of maltose-6'-P would have provided glucose-1,6-bisphosphate and glucose and formation of the latter product would have been measured as described above for the reaction with maltose. Attachment of the phosphoryl group to the reducing glucose moiety would have generated glucose-4-P and glucose-6-P. Formation of the latter compound would have been directly detected by the NADP-dependent glucose-6-P dehydrogenase reaction (see Experimental procedures). The malP gene therefore appeared to encode a protein with maltose (but not maltose-6'-P) phosphorylase activity (Fig. 1). Maltose metabolism by $E$. faecalis cannot therefore, follow the pathway previously proposed by (Le Breton et al., 2005).

\section{Inactivation of the maltose phosphorylase-encoding malP gene prevents maltose metabolism}

To resolve whether maltose phosphorylase participates in the metabolism of maltose taken up via the PTS transporter MalT, we first disrupted the malP gene (Fig. 1) and studied the effect of this mutation on maltose uptake and metabolism. First, the wild-type strain JH2-2 and the malP mutant, were grown in carbon-depleted M17 medium (Bizzini et al., 2010) supplemented with either maltose or glucose. While the wild-type strain grew equally well on glucose and maltose, the malP mutant failed to grow on maltose (Fig. 2A and B). Strain $\mathrm{JH} 2-2$ has previously been shown to efficiently transport $50 \mu \mathrm{M}\left[{ }^{14} \mathrm{C}\right]$-maltose via the PTS protein MalT. A malT mutant had almost completely lost maltose uptake. The slow $\left[{ }^{14} \mathrm{C}\right]-$ maltose uptake observed for the malT mutant was suggested to be catalyzed by the presumed maltodextrin ABC transport system MdxEFG (EFT41965-41967) (Fig. 1) (Le Breton et al., 2005). When carrying out identical transport studies with strain JH2-2 we observed that a significant part of the radioactivity associated with maltose was secreted into the medium in form of a negatively charged compound (Table 1). This was determined by passing an aliquot of the transport assay solution after centrifugation over an ion exchange column, which allowed separation of negatively charged compounds from uncharged or positively charged molecules (see Experimental procedures). The majority of the charged radioactive compound(s) is most likely lactic acid produced during maltose fermentation and subsequently secreted into the medium. $\left[{ }^{14} \mathrm{C}\right]$-Maltose transport studies with the malP mutant revealed that although it grew very poorly on maltose-containing medium, it accumulated about three times as much radioactivity as the wild-type strain (Fig. 3). Furthermore, in contrast to the wild-type strain the malP mutant secreted only a very small amount of charged radioactive compounds into the medium (Table 1). In summary, these results established that MalP plays an important role in the metabolism of maltose taken up via the PTS. While in the wild-type strain about half of the accumulated radioactive compounds (in the cell pellet after centrifugation of the transport assay mixture) were negatively charged, the radioactive compounds accumulated in the malP mutant were mainly (98\%) uncharged. It was likely that this uncharged intracellular radioactive compound was $\left[{ }^{14} \mathrm{C}\right]$-maltose, because all glycolytic intermediates carry a negative charge. The question therefore arose whether maltose is not phosphorylated during its transport by the PTS or whether it is phosphorylated during the transport, but subsequently dephosphorylated inside the cells.

\section{The gene downstream from malT encodes a maltose-6'-P phosphatase}

We first tested the hypothesis that maltose might be phosphorylated during its transport by the E. faecalis PTS and subsequently dephosphorylated inside the cell in order to serve as substrate for MalP. A clue for such a dephosphorylating activity came from transcription assays of the maltose utilization gene clusters in $S$. pyogenes. The homologues of malT and its downstream gene M5005_spy1691 were found to be cotranscribed in maltose-grown cells (Shelburne III et al., 2008), suggesting that the protein encoded by M5005_spy1691 
also plays a role in maltose metabolism. In E. faecalis $\mathrm{JH} 2-2$ the corresponding gene EFT41761 (Fig. 1A) encodes a protein annotated as a member of the endonuclease/ exonuclease/phosphatase family. We purified this protein after attaching a His-tag to its $\mathrm{N}$ terminus in order to test whether it plays indeed a role in maltose metabolism. By its annotation as an enzyme that putatively may hydrolyse phosphate esters we suspected that this protein might catalyze the dephosphorylation of intracellular maltose-6'-P to maltose. To test this hypothesis we used the same assay system employed for measuring a potential activity of maltose phosphorylase with maltose-6'-P. While no formation of NADPH occurred in the absence of EFT41761, a rapid increase in NADPH was observed when this protein was added to the assay mixture (Fig. 4). NADPH was also not formed when EFT41761 was present but maltose phosphorylase MalP was lacking in the assay mixture (data not shown). This result strongly suggested that EFT41761 dephosphorylates maltose-6'-P to maltose, which is subsequently cleaved by maltose phosphorylase into glucose-1-P and glucose. To unequivocally confirm the phosphatase activity we incubated maltose-6'-P in the presence and absence of EFT41761 and determined the resulting products by mass spectrometry (MS). In the absence of the enzyme we observed two peaks; one corresponding to maltose- 6 ' $-\mathrm{P}$ with one $\mathrm{Na}^{+}$ion $(\mathrm{MW}=445.08)$, the other corresponding to maltose-6'-P with two $\mathrm{Na}^{+}$ions $(\mathrm{MW}=467.07)$. In the sample incubated with EFT41761 these two peaks were no longer detectable and a new peak at 365.07 corresponding to unphosphorylated maltose with one bound $\mathrm{Na}^{+}$ion $(\mathrm{MW}=343+22)$ had appeared (Fig. 5A). This result unequivocally established that the gene downstream from malT, EFT41761, encodes an enzyme with maltose-6'-P phosphatase activity. The question mark in Fig. 1A can therefore be replaced with mapP.

To measure the kinetic parameters of the enzyme MapP we used a slightly modified coupled spectrophotometric assay with glucose dehydrogenase (see Experimental procedures). The $\mathrm{K}_{\mathrm{M}}$ of MapP was determined to be $4.1 \mathrm{mM}$ and the $\mathrm{V}_{\max }$ was found to be $25 \mu \mathrm{mol} \mathrm{min}{ }^{-1}$ $\mathrm{mg}^{-1}$ of protein providing a $\mathrm{k}_{\mathrm{cat}}$ of $128 \mathrm{sec}^{-1}$.

\section{MapP preferentially attacks disaccharide phosphates containing an $\alpha$-glycosidic bond}

In order to determine the specificity of the $E$. faecalis MapP enzyme we used commercially available glucose-6-P and fructose-6-P as potential substrates and in addition synthesized a variety of phosphorylated sugars and sugar derivatives (Table 2). The correct structure of these compunds was confirmed by thin-layer chromatography, mass spectrometry and NMR spectroscopy (Thompson, 2001). The phospho-sugars were incubated with MapP and the products of the reaction were analyzed by mass spectrometry. Neither glucose-6-P, fructose-6-P nor $\beta$-methylglucoside-6-P, which contain no or only a small aglycon, were dephosphorylated. Remarkably, MapP preferentially dephosphorylates glucopyranosylderived disaccharides and heterosides containing an O-a-glycosyl linkage. For example, the five a-linked-isomers of sucrose (maltulose-6'-P, leucrose-6'-P, trehalulose-6'-P, turanose-6'-P and palatinose-6'-P) were all entirely or significantly dephosphorylated by MapP (Table 2). Surprisingly, sucrose-6-P itself (which contains an $a(1 \leftrightarrow 2) \beta$ glycosidic linkage) was not dephosphorylated. Phosphorylated compounds containing an O- $\beta$ glycosidic bond (cellobiose-6'-P, gentiobiose-6'-P, arbutin-6-P, etc.,) were also not dephosphorylated by MapP. An exception was phosphorylated esculin, which was significantly dephosphorylated by MapP. In esculin, glucose is linked via a $\beta$-glycosidic linkage to the hydroxyl group in position 6 of the 6,7-dihydroxychromen-2-on (esculetol) molecule.

A question of considerable interest, was whether MapP would distinguish between phosphate groups bound to the first (non-reducing) and second (reducing) glucose moieties of maltose. To this end, doubly phosphorylated maltose was chemically synthesized, such that both glucose moieties carried a phosphoryl group at the C6-position (maltose-6',6- $\mathrm{P}_{2}$, 
for its formula, see Table 2). The structure and sites of phosphorylation of maltose-6',6- $\mathrm{P}_{2}$ were confirmed by thin-layer chromatography, mass spectrometry and NMR spectroscopy. Interestingly, only one of the phosphoryl groups was removed by MapP (compare Fig. 5C and $\mathrm{D}$ ). This must be the phosphate group attached to the 6'-position because if dephosphorylation had occurred at the 6-position of maltose-6',6- $\mathrm{P}_{2}$, maltose-6'-P would have been formed. As described above, maltose-6'-P is efficiently dephosphorylated by MapP leading to the formation of maltose, which, however, was not detected as a reaction product (Fig. 5D). In addition, compared to maltose-6'-P, the rate of dephosphorylation of doubly phosphorylated maltose was significantly slower. These results establish that MapP discriminates between phosphoryl groups bound to the 6- and 6'-position of maltose, and that phosphorylation at $\mathrm{C} 6$ of the reducing hexose impedes access of substrates to the active site. MapP therefore seems to interact not only with the non-reducing but also with the reducing glucose moiety of maltose.

Because the mass spectrometry experiments were carried out at saturating substrate concentrations (200 $\mathrm{mM}$ ) we used the malachite green assay (see Experimental procedures) (Baykov et al., 1988) which allows a more quantitative determination of the amount of phosphate liberated from the various phosphorylated substrates by the action of MapP. We used substrate concentrations of $2 \mathrm{mM}$, which is in the $\mathrm{K}_{\mathrm{M}}$ range for maltose-6'-P. Under these conditions we observed that only turanose- 6 ' $-\mathrm{P}$ was similarly efficiently dephosphorylated as maltose-6'-P (85\% of the activity of maltose-6'-P) (Table 2). The other four a-linked-isomers of sucrose were dephosphorylated with an efficiency ranging from $0.9 \%$ for palatinose-6'-P to $18.8 \%$ for leucrose-6'-P. Dephosphorylation of maltose-6',6- $\mathrm{P}_{2}$ was about 15 -fold slower than dephosphorylation of maltose-6'-P, thus confirming the inhibitory effect of modifications at the reducing sugar moiety of maltose. Finally, esculin-6-P, the only $\beta$-glycoside dephosphorylated by MapP, exhibited $0.6 \%$ of the activity obtained with maltose-6'-P, indicating that MapP has only weak affinity for this compound but according to the mass spectrometry data can efficiently dephosphorylate it at high concentrations (Table 2). We also tested MapP-catalyzed dephosphorylation with glucose-6$\mathrm{P}$, fructose-6-P and sucrose-6-P, but in agreement with the mass spectrometry data no activity was observed.

\section{The mapP mutant accumulates maltose-6'-P}

To confirm the role of MapP in maltose fermentation, we constructed a mapPmutant and tested its ability to utilize glucose or maltose as carbon source. Surprisingly, in glucosecontaining carbon-depleted M17 medium the mapP mutant grew significantly and reproducibly faster than the wild-type strain (Fig. 2). We have no explanation for this observation. In contrast to the malP strain, the mapP mutant was able to grow in maltosecontaining medium, although at significantly slower rate than the wild-type strain. The mapP mutant probably slowly takes up maltose via the maltodextrin $\mathrm{ABC}$ transport system, which exhibits low affinity for maltose (Le Breton et al., 2005). Maltose taken up by the $\mathrm{ABC}$ transporter can be directly metabolized via MalP (see Fig. 6). MalP is therefore necessary for the metabolism of maltose taken up by both, the PTS and the ABC transport system, which explains why the malP mutant had lost the capacity to grow on maltose.

We subsequently studied the effect of the mapP mutation on maltose transport and metabolism. As expected from the growth experiments, the mapP mutant was able to transport $\left[{ }^{14} \mathrm{C}\right]$-maltose. However, the amount of radioactivity accumulated inside the cells after $5 \mathrm{~min}$ incubation with $55 \mu \mathrm{M}\left[{ }^{14} \mathrm{C}\right]$-maltose was about 10-times higher than in the wild-type strain and 3.5-times higher than in the malP mutant (Fig. 3). It should be noted that these results do not reflect the true transport activity, because, as mentioned above, in the wild-type strain a major part of maltose is secreted as charged compounds into the medium. In contrast to the wild-type strain, the mapP mutant secreted only a very small 
amount of the radioactivity into the medium, which is probably lactate formed from maltose taken up by the maltodextrin $\mathrm{ABC}$ transport system and metabolized via MalP. When we used $250 \mu \mathrm{M}\left[{ }^{14} \mathrm{C}\right]$-maltose the uptake via the $\mathrm{ABC}$ transport system increased significantly as deduced from the elevated amount of secreted, negatively charged radioactive compounds (data not shown). Most of the radioactivity accumulated by the mapP mutant (in the cell pellet after centrifugation of the transport assay mixture) was present in negatively charged form, presumably as maltose-6'-P (Table 1). In order to confirm this assumption we incubated an aliquot of the intracellularly accumulated radioactive compounds with purified MapP. We observed that in the presence of MapP more than $90 \%$ of the intracellularly accumulated negatively charged radioactive compounds were converted into uncharged compounds (Table 2), suggesting that the mapP mutant accumulates primarily maltose-6'-P when exposed to a maltose-containing growth medium. The lower amount of accumulated radioactive maltose observed for the malP mutant compared to $\operatorname{map} P$ (Fig. 3) is probably due to the fact that the latter continues to produce energy by taking up maltose via the ABC transporter and metabolizing it via MalP (Fig. 6).

\section{Heterologous complementation of a $B$. subtilis malA $m d x G$ double mutant with $E$. faecalis mapP}

In order to demonstrate that $E$. faecalis MapP can dephosphorylate maltose-6'-P in vivo also in other bacteria we constructed a $B$. subtilis malA mutant, which was expected to accumulate maltose-6'-P owing to the loss of the 6-P-a-glucosidase activity (Thompson et al., 1998). We also inactivated the $m d x G$ (former $y v d I$ ) gene, which encodes a membrane component of the maltodextrin-specific ABC transporter (Schönert et al., 2006) in order to prevent low affinity maltose transport via this uptake system. For this purpose we inserted the pMUTIN plasmid (Vagner et al., 1998) into this gene, which caused not only $m d x G$ inactivation but also allowed the IPTG-inducible expression of the downstream genes, including $y v d K$, which codes for a protein with high similarity to maltose phosphorylases (Schönert et al., 2006) (Fig. 1). The resulting double mutant had lost the capacity to grow on minimal medium containing maltose as the sole carbon source. We expected that heterologous complementation of this strain with the E. faecalis mapP gene cloned into the integrative plasmid pAC7 (Weinrauch et al., 1991) would lead to dephosphorylation of the accumulated maltose-6'-P and therefore restore growth on maltose. In order to test this assumption the $E$. faecalis mapP gene was fused to the constitutive promoter and the Shine Dalgarno box of the $B$. subtilis pts $H$ gene and inserted into the amyE locus of the malA $m d x G$ double mutant. When the empty pAC7 plasmid was inserted into this mutant no growth on IPTG-containing maltose minimal medium was observed. Similarly, when the double mutant was complemented with mapP and incubated in maltose minimal medium without IPTG no growth occurred after $36 \mathrm{~h}$. Only when IPTG was included, which leads to the expression of the genes downstream from $m d x G$, the mapP-complemented malA $m d x G$ double mutant was able to grow on maltose-containing minimal medium at about half the growth rate of the wild-type strain (data not shown). These results suggest that MapP converts maltose-6'-P accumulated by the B. subtilis malA mutant into maltose, which is subsequently converted into glucose-1-P and glucose by the maltose phosphorylase YvdK. In agreement with this concept, the absence of MapP or the absence of induction of the $y v d K$ gene prevented growth of the malA $m d x G$ double mutant on maltose minimal medium.

\section{Discussion}

We established in this study that the uptake of maltose by a PTS and its subsequent metabolism in E. faecalis follow a quite unusual mechanism. As outlined in Fig. 6, maltose transported by the PTS enters the cells as maltose-6'-P. It is subsequently dephosphorylated 
to maltose inside the cells by the maltose-6'-P phosphatase MapP. By using inorganic phosphate, the maltose phosphorylase MalP phosphorolyses the resulting intracellular maltose into glucose and glucose-1-P, which are both converted into the glycolytic metabolite glucose-6-P. MapP is a member of the endonuclease/exonuclease/phosphatase family, which includes enzymes with quite different activities, such as DNase I or synaptojanin, a phosphatidylinositol-3,4,5-trisphosphate 5-phosphatase (Woscholski et al., 1997). The kinetic parameters determined for $\operatorname{MapP}\left(\mathrm{K}_{\mathrm{M}}=4.1 \mathrm{mM}, \mathrm{V}_{\max }=25 \mu \mathrm{mol} \mathrm{min}{ }^{-1}\right.$ $\mathrm{mg}^{-1}$ protein; $\mathrm{k}_{\mathrm{cat}}=128 \mathrm{sec}^{-1}$ ) are within the usual range of catabolic enzymes.

The presence of the two genes coding for the PTS permease MalT and the maltose-6'-P phosphatase MapP and their identical arrangement in most enterococci and streptococci, such as $S$. mutans (Webb et al., 2007), S. pyogenes (Shelburne III et al., 2008) and $S$. pneumoniae (Bidossi et al., 2012) suggest that this kind of maltose utilization is a general phenomenon in these bacterial species. In some streptococci, such as Streptococcus gallolyticus and Streptococcus gordonii, MapP was called RgfB (regulator of fibrinogen binding). In $S$. agalactiae, $r g f B$ is also located downstream from malT. Nevertheless, $r g f B$ was reported to be co-transcribed with genes encoding a two component sensor kinase and response regulator (Spellerberg et al., 2002). Inactivation of the histidine kinase RgfC affected fibrinogen binding, but it is not known whether alterations in $\operatorname{rgfB}(\operatorname{map} P)$ expression are responsible for this phenotype. Several bacillales (Macrococcus caseolyticus, Paenibacillus polymyxa, Bacillus cereus, etc.) and clostridiales (Catonella morbi, Clostridium botulinum, Clostridium perfringens, etc.) also possess homologues of MalT and MapP. In these organisms, a PTS permease of the glucose subfamily was probably adapted to transport maltose. Indeed, MalT resembles more the glucose-specific PTS transporter PtsG of $B$. subtilis than the maltose-specific MalP. The PTS-mediated uptake of maltose leads to the formation of intracellular maltose-6'-P, which in other bacteria is hydrolyzed into glucose and glucose-6-P by the $\mathrm{NAD}^{+} / \mathrm{Mn}^{2+}$-dependent 6-P-a-glucosidase. Enterococci and streptococci generally lack the maltose-6'-P hydrolase enzyme. Instead enterococci contain upstream from the malT gene, which encodes the maltose-specific PTS transporter, an operon encoding three enzymes for the catabolism of maltose taken up without phosphorylation by $\mathrm{ABC}$ transporters or ion-symporting permeases (Le Breton et al., 2005). In fact, in several organisms containing a LacY-like maltose permease MalY (Lohmiller et al., 2008) the transporter gene malY is followed by the three genes malP-pgcM-malM encoding maltose phosphorylase, phosphoglucomutase and mutarotase (A. Mazé and J. Deutscher, unpublished observation). It is therefore tempting to assume that enterococci and streptococci acquired these genes from one of the organisms using MalY for maltose transport. These organisms therefore seem to synthesize a protein for maltose transport (MalT, produces maltose-6'-P), which at the first glance does not seem to be connected to a catabolic route (MalP uses only maltose as substrate). In order to endow enterococci and all other bacteria possessing a malThomologue with the capacity to catabolize maltose-6'-P formed during PTS-catalyzed maltose transport, these organisms needed an additional enzyme connecting the PTS uptake route to the maltose phosphorylase-mediated catabolic pathway. For that purpose these bacteria probably acquired the gene located downstream from malT, which encodes an enzyme belonging to the large endonuclease/exonuclease/ phosphatase family. During the course of evolution it was probably optimized for the dephosphorylation of phosphorylated a-glucosides, such as maltose-6'-P.

Acquiring a maltose-6'-P phosphatase provided probably an optimal connection between PTS-mediated maltose uptake, and maltose phosphorylase-catalyzed metabolism. Importantly, the number of ATP molecules formed from maltose taken up via an ABC transport system and phosphorolyzed by maltose phosphorylase, or transported via a PTS and hydrolyzed by a 6-P-a-glucosidase, is principally identical to that obtained by the MapP-catalyzed metabolism of maltose-6'-P formed during MalT-catalyzed transport. 
Although MapP dephosphorylates intracellular maltose-6'-P in the first catabolic step by producing Pi and maltose, MalP subsequently uses Pi for the phosphorolysis of the resulting maltose in order to form glucose-1-P and glucose. The enzyme phosphoglucomutase encoded by the gene EFT41758 (Fig. 1A) converts glucose-1-P into glucose-6-P. Glucose and glucose-6-P are also formed when B. subtilis MalA hydrolyzes maltose-6'-P taken up via the PTS permease MalP (Fig. 1B). The number of ATP and PEP molecules used for maltose transport and the catabolic intermediates are therefore identical for all three different modes of maltose transport and metabolism.

\section{Experimental procedures}

\section{Bacterial strains and growth conditions}

The bacterial strains used in this study are listed in Table 4. E. faecalis strains were routinely grown at $37^{\circ} \mathrm{C}$ without shaking in $100 \mathrm{ml}$ sealed bottles filled with 20 to $50 \mathrm{ml}$ of LuriaBertani medium (LB; Difco, New Jersey, USA) containing $0.5 \%$ w/v glucose. Growth curves were obtained with carbon-depleted M17MOPS medium, which was prepared as previously described (Bizzini et al., 2010). It was supplemented with either $0.5 \% \mathrm{w} / \mathrm{v}$ glucose or $0.5 \% \mathrm{w} / \mathrm{v}$ maltose. Erythromycin and tetracycline were added when appropriate at concentrations of $150 \mu \mathrm{g} \mathrm{ml}^{-1}$ and $5 \mu \mathrm{g} \mathrm{ml}^{-1}$, respectively.

B. subtilis strains were grown aerobically at $37^{\circ} \mathrm{C}$ in $\mathrm{LB}$ medium or in minimal salts medium C containing $0.005 \%$ w/v tryptophan (Darbon et al., 2002), and supplemented with $0.5 \% \mathrm{w} / \mathrm{v}$ glucose or $0.5 \% \mathrm{w} / \mathrm{v}$ maltose, as indicated. Antibiotics were used at the following concentrations: $5 \mu \mathrm{g} \mathrm{ml}^{-1}$ kanamycin and $0.3 \mu \mathrm{g} \mathrm{ml}{ }^{-1}$ erythromycin. Conventional transformation of $B$. subtilis was performed by following a published procedure (Anagnostopoulos and Spizizen, 1961). E. coli strains were grown aerobically in LB medium at $37{ }^{\circ} \mathrm{C}$ and transformed by electroporation with a Gene Pulser apparatus (Bio-Rad Laboratories). Aerobic growth of $B$. subtilis and $E$. coli strains was achieved by gyratory shaking at $250 \mathrm{rpm}$, and was monitored at $\mathrm{A}_{600 \mathrm{~nm}}$ in a Novaspec II spectrophotometer.

\section{Purification of His-tagged E. faecalis maltose phosphorylase and maltose-6-P phosphatase}

In order to purify maltose phosphorylase and maltose-6-P phosphatase the corresponding genes malP and map $P$ were amplified by PCR using chromosomal $E$. faecalis JH2-2 DNA as template and the two primer pairs EfMalP_Up/EfMallP_Lo and Ef0960BamF/Ef0960SalR, respectively (Table 5). The amplimers were cut with the appropriate restriction enzymes (BamHI/KpnI or BamHI/SalI) and cloned into the His-tag expression vector pQE30 cut with the same enzymes. The correct sequence of the two genes was confirmed by DNA sequencing and purification of the His-tagged proteins was carried out as previously described (Martin-Verstraete et al., 1999).

\section{Spectrophotometric assays of maltose phosphorylase and maltose-6'-P phosphatase activities}

Maltose phosphorylase activity was determined by using a coupled spectrophotometric assay, in which glucose formed from maltose by maltose phosphorylase was converted with ATP and hexokinase into glucose-6-P, which was subsequently oxidized to gluconate-6-P in an NADP-requiring reaction catalyzed by glucose-6-P dehydrogenase. In order to determine the amount of glucose we used the glucose assay reagent of Sigma-Aldrich $\left(30 \mathrm{mg} \mathrm{ml}^{-1}\right)$ and followed the formation of NADPH by measuring the A $_{340 \mathrm{~nm}}$ with a Kontron Bio-Tek spectrophotometer using the autorate program. The assay mixture contained $500 \mu \mathrm{l}$ glucose assay reagent, $500 \mu \mathrm{l} 50 \mathrm{mM}$ phosphate buffer, $\mathrm{pH} 7.0,10 \mathrm{mM} \mathrm{MgCl}_{2}, 1 \mathrm{mM}$ maltose and $20 \mu \mathrm{l}$ maltose phosphorylase $\left(1.2 \mathrm{mg} \mathrm{ml}^{-1}\right)$. When maltose was replaced with maltose-6'-P 
in the assay mixture no increase of the absorption at $340 \mathrm{~nm}$ was observed. However, when $40 \mu \mathrm{l}$ maltose-6'-P phosphatase (MapP, $0.8 \mathrm{mg} \mathrm{ml}^{-1}$ ) was added to the assay mixture containing maltose-6'-P an increase of the absorption at $340 \mathrm{~nm}$ similar to that detected with maltose and maltose phosphorylase was observed.

To determine the $\mathrm{k}_{\mathrm{cat}}$ and $\mathrm{K}_{\mathrm{M}}$ values of Map we slightly modified the assay conditions by replacing the glucose assay kit (eznymes hexokinase and glucose-6-P dehydrogenase) with 5 $\mu \mathrm{g}$ of NADH-dependent glucose dehydrogenase (Sigma). The assay mixture therefore contained $30 \mathrm{mM}$ NADH in a total volume of $450 \mu$. The concentration of maltose- 6 '-P varied from 0.22 to $30 \mathrm{mM}$. All other conditions were as described above. This assay system reacted more quickly to the formation of glucose and therefore allowed a more accurate determination of the kinetic parameters of MapP.

\section{Construction of an E. faecalis malP defective strain}

A mutant defective in maltose phosphorylase was constructed by interrupting the malP gene by single recombination using the thermosensitive vector pGhost 8 (Maguin et al., 1996). An internal fragment of the malP gene was amplified by PCR using chromosomal DNA of $E$. faecalis JH2-2 as template and the primer pair EfMalPmut_U/EfMalPmut_L. The amplimer was digested with appropriate restriction enzymes (HindIII and EcoRI) and ligated into pGhost 8 cut with the same enzymes. The resulting plasmid was named pGh-malP and used to transform E. coli EC101 (Table 4). Purified pGh-malP was electroporated into E. faecalis JH2-2 by following a previously described method (Friesenegger et al., 1991). Plasmid integration was induced as previously described (Maguin et al., 1996). Briefly, transformants are grown overnight at the permissive temperature $\left(30^{\circ} \mathrm{C}\right)$ in $\mathrm{LB}$ medium containing glucose and $5 \mathrm{\mu g} \mathrm{ml}^{-1}$ tetracycline for plasmid maintenance before an aliquot of the culture was used to inoculate fresh medium (1:500-fold dilution) which was incubated at the restrictive temperature $\left(37^{\circ} \mathrm{C}\right)$ thus preventing plasmid replication. When the culture reached an $\mathrm{OD}_{600}$ of 0.5 , serial dilutions were plated on solid LB medium containing glucose and the antibiotic and incubated at $37^{\circ} \mathrm{C}$. A single clone was isolated and the interruption of malP was confirmed by its maltose-negative phenotype and by PCR. The malP-deficient strain was called JH-malP (Table 4).

\section{Construction of an $E$. faecalis mapP mutant}

A mutant deficient in maltose-6'-P phosphatase was constructed by interrupting the $E$. faecalis mapP gene by single recombination using the suicide vector pUCB30bis (Benachour et al., 2007) (Table 4). An internal fragment of mapP was amplified by using chromosomal DNA of E. faecalis $\mathrm{JH} 2-2$ as template and the primer pair MapPBamF/ MapPEcoR (Table 5). The amplimer was digested with the restriction enzymes BamHI and EcoRI and ligated into pUCB30bis cut with the same enzymes. The purified plasmid was used to transform E. faecalis JH2-2 by electroporation (Friesenegger et al., 1991) and an erythromycin-resistant clone was isolated and called AB01 (Table 4). The correct integration of the plasmid was verified by PCR by using oligo EfmapPconf in combination with a vector-based primer (Table 5).

\section{Maltose transport studies with $\left[{ }^{14} \mathrm{C}\right]$-maltose}

Transport studies with $\left[{ }^{14} \mathrm{C}\right]$-maltose were carried out as previously described (Viana et al., 2000). Cells of the E. faecalis wild-type strain JH2-2 and the malP and mapP mutants derived from it were grown in $25 \mathrm{ml} \mathrm{LB}$ medium containing $0.5 \%$ maltose to an $\mathrm{OD}_{600}$ of 0.5. Cells were centrifuged and washed twice with $50 \mathrm{mM}$ Tris- $\mathrm{HCl}$ buffer, $\mathrm{pH} 7.4$, containing $10 \mathrm{mM} \mathrm{MgCl}$. The cells were resuspended in such a volume of $50 \mathrm{mM}$ Trismaleate buffer, $\mathrm{pH} 7.2$, containing $5 \mathrm{mM} \mathrm{MgCl}_{2}$ that the cell suspension exhibited an $\mathrm{OD}_{600}$ of 10. For maltose transport assays $50 \mu \mathrm{l}$ of the cell suspension was diluted with $0.5 \mathrm{ml}$ 
transport buffer (resuspension buffer containing 1\% peptone) and preincubated $1 \mathrm{~min}$ at $37^{\circ} \mathrm{C}$. The transport reaction was started by adding $60 \mu \mathrm{l}$ of a $\left[{ }^{14} \mathrm{C}\right]$-maltose solution composed of $54 \mu \mathrm{l} 0.5 \mathrm{mM}$ maltose plus $6 \mu \mathrm{l}\left[{ }^{14} \mathrm{C}\right]$-maltose $\left(0.1 \mathrm{mCi} \mathrm{ml}^{-1}\right.$ ) (corresponds to $\left.1.33 \times 10^{6} \mathrm{cpm}\right)$. The final maltose concentration in the assay mixture was calculated to be $55 \mu \mathrm{M}$. Aliquots of $100 \mu \mathrm{l}$ were withdrawn after $0.25,0.75,1.5,2.5$ and $5 \mathrm{~min}$ and mixed with $5 \mathrm{ml}$ of cold resuspension buffer before they were filtered through $0.45 \mu \mathrm{m}$ pore-size filters (Schleicher und Schuell, Dassel, Germany) and washed twice with $5 \mathrm{ml}$ resuspension buffer. The filters were dried and the radioactivity retained was determined by liquid scintillation counting.

\section{Isolation and characterization of negatively charged radioactive compounds accumulated during $\left[{ }^{14} \mathrm{C}\right]$-maltose uptake}

E. faecalis wild-type and mutant cells were grown as described above and a $275 \mu \mathrm{l}$ assay mixture for $\left[{ }^{14} \mathrm{C}\right]$-maltose uptake was prepared for each strain as described above. The cells were incubated for $5 \mathrm{~min}$ in the presence of $\left[{ }^{14} \mathrm{C}\right]$-maltose before a $100 \mu \mathrm{l}$ aliquot was withdrawn and filtered through a $0.45 \mu \mathrm{m}$ pore-size filter. Another $60 \mu \mathrm{l}$ aliquot was rapidly centrifuged and supernatant and cell pellet were separated. The cell pellet was resuspended in $100 \mu \mathrm{l}$ boiling water to obtain a cell extract. The supernatants and the cell extracts were loaded on $1 \mathrm{ml}$ Dowex AG1-X8 anion exchange columns which were washed three times with $2 \mathrm{ml}$ of water in order to remove uncharged or positively charged compounds. The flow through and the wash fractions were collected, combined and the radioactivity was determined by liquid scintillation counting. Negatively charged compounds were subsequently eluted with three times $1.5 \mathrm{ml} 1 \mathrm{M} \mathrm{LiCl}$ and the radioactivity was determined by liquid scintillation counting.

In order to test whether treating the negatively charged radioactive compounds accumulated by the mapP mutant with maltose-6'-P phosphatase would convert part of them into uncharged compounds strain mapP was allowed to take up $\left[{ }^{14} \mathrm{C}\right]$-maltose before a cell extract was prepared as described above. A $180 \mu \mathrm{l}$ aliquot of the transport assay was withdrawn, centrifuged and the cells were desintegrated in $300 \mu \mathrm{l}$ of boiling water. To one $100 \mu \mathrm{l}$ aliquot of cell extract $50 \mu \mathrm{l}$ Tris/ $\mathrm{HCl}, \mathrm{pH} 7.4$ and $20 \mu \mathrm{l} 100 \mathrm{mM} \mathrm{MgCl}_{2}$ were added, whereas to the second $100 \mu \mathrm{l}$ aliquot $50 \mu \mathrm{l}$ of purified MapP dissolved in $50 \mu \mathrm{l} \mathrm{Tris} / \mathrm{HCl}, \mathrm{pH}$ $7.4\left(0.8 \mathrm{mg} \mathrm{ml}^{-1}\right)$ was added. The samples were incubated for $1 \mathrm{~h}$ at $37^{\circ} \mathrm{C}$ before charged and uncharged radioactive compounds were determined as described above.

\section{Synthesis of phosphorylated sugars and sugar derivatives}

Phosphorylated O-a-linked disaccharides, including maltose-6'-phosphate, were prepared enzymatically via the a-glucoside specific PTS present in palatinose-grown cells of Klebsiella pneumoniae (Thompson, 2001). Phosphorylation of the primary hydroxyl (C6') group of the non-reducing glucose moiety in O- $\beta$-linked disaccharides was as previously described (Thompson et al., 2002). In brief, phosphorylation was effected by incubation of the disaccharides with ATP-dependent $\beta$-glucoside kinase (BglK, EC 2.7.1.85) from $K$. pneumoniae. Phosphorylated derivatives of both $\alpha$ - and $\beta$-linked disaccharides were isolated by ethanol and $\mathrm{Ba}^{2+}$ precipitation, and further purified by ion-exchange and paper chromatography. Structures and product purity were confirmed by thin-layer chromatography, mass spectrometry and NMR spectroscopy. The chromogenic analog, pnitrophenyl-a-D-glucopyranoside 6-phosphate (pNPaG6P) was prepared by phosphorylation of the C6 hydroxyl moiety of pNP-a-D-glucopyranoside with phosphorus oxychloride in trimethyl phosphate containing a small amount of water (Thompson et al., 1995). Treatment of maltose under the latter conditions, causes non-selective phosphorylation at both $\mathrm{C} 6$ and $\mathrm{C} 6$ ' primary hydroxyl groups of the disaccharide, producing a mixture of maltose-6'6-diphosphate (maltose-6',6- $\mathrm{P}_{2}$ ), maltose-6'P and maltose-6P. 
Maltose-6',6- $\mathrm{P}_{2}$ was separated from the two mono-phosphate derivatives by gradient elution $\left(0-0.5 \mathrm{M} \mathrm{NH}_{4} \mathrm{HCO}_{3}\right)$ from a column of AG1-X8 (formate-form) ion exchange resin.

Bicarbonate was removed by lyophilization, and maltose- 6 ',6- $\mathrm{P}_{2}$ was purified as described above. Its correct structure was confirmed by thin-layer chromatography, mass spectrometry and NMR spectroscopy.

\section{Mass spectrometric analysis of phosphorylated compounds treated with MapP}

Solutions containing the various phosphorylated sugars and sugar derivatives listed in Table 2 at a concentration of $2 \mathrm{M}$ were prepared. $5 \mu \mathrm{l}$ aliquots of these solutions were added to either $40 \mu \mathrm{l}$ of purified MapP $\left(0.8 \mathrm{mg} \mathrm{ml}^{-1}\right.$, dialyzed against $20 \mathrm{mM}$ ammonium bicarbonate) or to $40 \mu \mathrm{l}$ of $20 \mathrm{mM}$ ammonium bicarbonate and incubated for $2 \mathrm{~h}$ at $37^{\circ} \mathrm{C}$. The samples were subsequently lyophilized and rehydrated with $10 \mu \mathrm{l}$ of water. Aliquots of $1 \mu \mathrm{l}$ were mixed with $9 \mu \mathrm{l}$ of a sugar matrix solution and $1 \mu \mathrm{l}$ was spotted onto the MALDI steel plate. The sugar matrix was freshly prepared and contained $100 \mu \mathrm{g} / \mathrm{ml} 2,5-$ dihydroxybenzoic acid dissolved in a mixture of H2O/acetonitrile/N,N-Dimethylaniline $(1: 1: 0.02 \mathrm{vol} / \mathrm{vol})$. The samples were analyzed by MALDI-TOF MS (Voyager DE super STR, AB SCIEX) by irradiating them with a nitrogen laser $(337 \mathrm{~nm}, 10 \mathrm{~Hz})$ integrated in this instrument and recording mass spectra in the reflectron mode using a delay extraction time of $120 \mathrm{~ns}$ and a m/z mass range between 200 and $600 \mathrm{Da}$.

\section{Detection of MapP-catalyzed formation of phosphate with the malachite green assay}

To follow MapP-catalyzed dephosphorylation of the different phospho-compounds over various time periods we used the malachite green assay (Baykov et al., 1988).

Dephosphorylation experiments were carried out in $650 \mu$ assay mixtures containing $50 \mathrm{mM}$ Tris/ $\mathrm{HCl}, \mathrm{pH} 7.4,5 \mathrm{mM} \mathrm{MgCl} 2$ and $2 \mathrm{mM}$ of the phosphorylated compounds. The reaction was started by adding MapP and the samples were incubated for various time periods at $37^{\circ} \mathrm{C}$. For each phospho-compound the amount of MapP (ranging from $40 \mu \mathrm{g}$ to $4 \mathrm{mg}$ MapP) was adjusted in such a way that it led to detectable formation of phosphate within 6 min incubation. Aliquots of $100 \mu \mathrm{l}$ were withdrawn after 0, 1.5, 3, 6, 10 and $20 \mathrm{~min}$ incubation and immediately mixed with $25 \mu \mathrm{l}$ of the malachite green reagent (Baykov et al., 1988). The samples were kept for $20 \mathrm{~min}$ at ambient temperature before $375 \mu \mathrm{l}$ of water was added and the $\mathrm{OD}_{630}$ determined. In Table 2, the activity measured with the various phospho-compounds is expressed relative to the activity measured with maltose-6'-P, which was set to $100 \%$.

\section{Construction of a $B$. subtilis malA deletion mutant}

In order to construct a malA mutant we amplified by PCR a 2150 bp fragment covering the entire mal $A$ gene and upstream and downstream regions by using $B$. subtilis DNA as template and the primer pair malAForBam and malARevKpn (Table 5). The amplicon was cut with BamHI and KpnI and cloned into pUC18 cut with the same enzymes. The resulting plasmid was digested with the restriction enzyme ClaI, which led to the deletion of a $328 \mathrm{bp}$ fragment in the middle of malA and also introduced a frame shift. The shortened insert of pUC18 was cut out with BamHI and KpnI and cloned into the vector pMAD (Arnaud et al., 2004) digested with the same enzymes. The resulting plasmid was used to transform $B$. subtilis wild-type strain 168 . The plasmid pMAD contains a temperature-sensitive pE194 origin of replication. In order to obtain a malA mutant by double cross over we followed a previously described protocol (Aké et al., 2011). The correct deletion and the insertion of a frame shift mutation in the malA gene in one of the isolated strains were confirmed by carrying out a PCR amplification with the primer pair VerifMalAFor and VerifMalARev (Table 5), which led to the amplification of a $589 \mathrm{bp}$ fragment instead of the $1012 \mathrm{bp}$ fragment obtained for the wild-type strain 168. This strain was called AM01. 


\section{Construction of a $B$. subtilis malA $m d x G$ double mutant}

In order to inactivate one of the membrane components of the $B$. subtilis maltodextrin transporter, which also catalyzes slow uptake of maltose (Schönert et al., 2006), an internal DNA fragment of the $m d x G$ gene was amplified by PCR with primers mdxGForHind and mdxGRevBam. The amplimer was digested with HindIII and BamHI and cloned into pMUTIN4 (Vagner et al., 1998) cut with the same enzymes thus providing pMUTIN-mdxG. B. subtilis AM01 was transformed with this plasmid to obtain strain AM02 (Table 4), in which transcription of the genes downstream from the disrupted $m d x G$ is under control of the IPTG-inducible Pspac promoter. Proper integration of the plasmid was confirmed by PCR.

\section{Complementation of the $B$. subtilis malA $m d x G$ mutant with $E$. faecalis mapP}

The $B$. subtilis pts $H$ promoter and Shine Dalgarno box were amplified with oligos ptsHPromForEco and ptsHPromRevBam and cloned into the EcoRI/BamHI sites of pAC7 providing pAC7-PptsH. Subsequently, the E. faecalis mapP gene was amplified using primers mapPForBam and mapPRevSac and cloned into the BamHI/SacI sites of pAC7PptsH. In the resulting plasmid pAC7-PptsH-mapP (Table 4) the mapP gene is expressed under control of the constitutive $p t s H$ promoter. It was inserted into the amyE locus of the $B$. subtilis 168 chromosome. Kanamycin-resistant integrants resulting from homologous recombination were selected. Integration into the $a m y E$ locus was confirmed by an amylasenegative phenotype of cells plated on LB agar containing soluble starch (Harwood and Cutting, 1980).

\section{Acknowledgments}

We thank Tarek Msadek and Dusko Ehrlich for vectors pAC7 and pMUTIN, respectively, and Eliane Milohanic for providing us with a plasmid containing the promoter and Shine-Dalgarno box of $B$. subtilis ptsH. We are grateful to Isabelle Rincé for technical assistance during construction of the mapP mutant. This work was supported by grants from the MinCyt/ECOS-Sud programme (Action $\mathrm{N}^{\circ}$ A09B03) (C.M. and J.D), the Agencia Nacional de Promoción y Tecnológica (AN-PCyT, contract 2010-1828 and 2008-1562; Argtentina) (C.M.), and the Intramural Research Program of the NIDCR, National Institutes of Health, Department of Health and Human Services, Bethesda, Maryland 20892 (J.T.). G.R. is a fellow researcher of CONICET (Argentina), and V.B. and C.M. are Career Investigators of CONICET (Argentina).

\section{References}

Aké FMD, Joyet P, Deutscher J, Milohanic E. Mutational analysis of glucose transport regulation and glucose-mediated virulence gene repression in Listeria monocytogenes. Mol Microbiol. 2011; 81:274-293. [PubMed: 21564334]

Anagnostopoulos C, Spizizen J. Requirements for transformation in Bacillus subtilis. J Bacteriol. 1961; 81:741-746. [PubMed: 16561900]

Andersson U, Levander F, Rådström P. Trehalose-6-phosphate phosphorylase is part of a novel metabolic pathway for trehalose utilization in Lactococcus lactis. J Biol Chem. 2001; 276:4270742713. [PubMed: 11553642]

Andersson U, Rådström P. $\beta$-Glucose 1-phosphate-interconverting enzymes in maltose- and trehalosefermenting lactic acid bacteria. Environ Microbiol. 2002; 4:81-88. [PubMed: 11972617]

Arnaud M, Chastanet A, Débarbouillé M. New vector for efficient allelic replacement in naturally nontransformable, low-GC-content, gram-positive bacteria. Appl Environ Microbiol. 2004; 70:6887-6891. [PubMed: 15528558]

Baykov AA, Evtushenko OA, Avaeva SM. A malachite green procedure for orthophosphate determination and its use in alkaline phosphatase-based enzyme immunoassay. Anal Biochem. 1988; 171:266-270. [PubMed: 3044186] 
Benachour A, Auffray Y, Hartke A. Construction of plasmid vectors for screening replicons from gram-positive bacteria and their use as shuttle cloning vectors. Curr Microbiol. 2007; 54:342-347. [PubMed: 17486410]

Bidossi A, Mulas L, Decorosi F, Colomba L, Ricci S, Pozzi G, Deutscher J, Viti C, Oggioni MR. A functional genomics approach to establish the complement of carbohydrate transporters in Streptococcus pneumoniae. PLoS One. 2012; 7:e33320. [PubMed: 22428019]

Bizzini A, Zhao C, Budin-Verneuil A, Sauvageot N, Giard JC, Auffray Y, Hartke A. Glycerol is metabolized in a complex and strain-dependent manner in Enterococcus faecalis. J Bacteriol. 2010; 192:779-785. [PubMed: 19966010]

Cantarel BL, Coutinho PM, Rancurel C, Bernard T, Lombard V, Henrissat B. The CarbohydrateActive EnZymes data-base (CAZy): an expert resource for glycogenomics. Nucleic Acids Res. 2009; 37:D233-D238. [PubMed: 18838391]

Creti R, Koch S, Fabretti F, Baldassarri L, Huebner J. Enterococcal colonization of the gastrointestinal tract: role of biofilm and environmental oligosaccharides. BMC Microbiol. 2006; 6:60. [PubMed: 16834772]

Darbon E, Servant P, Poncet S, Deutscher J. Antitermination by GlpP, catabolite repression via CcpA, and inducer exclusion elicited by $\mathrm{P} \sim \mathrm{GlpK}$ dephosphorylation control Bacillus subtilis glpFK expression. Mol Microbiol. 2002; 43:1039-1052. [PubMed: 11929549]

Daus ML, Grote M, Schneider E. The MalF P2 loop of the ATP-binding cassette transporter MalFGK2 from Escherichia coli and Salmonella enterica serovar typhimurium interacts with maltose binding protein (MalE) throughout the catalytic cycle. J Bacteriol. 2009; 191:754-761. [PubMed: 19047355]

Dippel R, Boos WJ. The maltodextrin system of Escherichia coli: metabolism and transport. J Bacteriol. 2005; 187:8322-8331. [PubMed: 16321936]

Friesenegger A, Fiedler S, Devriese LA, Wirth R. Genetic transformation of various species of Enterococcus by electroporation. FEMS Microbiol Lett. 1991; 63:323-327. [PubMed: 1905659]

Gopal S, Berg D, Hagen N, Schriefer EM, Stoll R, Goebel W, Kreft J. Maltose and maltodextrin utilization by Listeria monocytogenes depend on an inducible ABC transporter which is repressed by glucose. PLoS One. 2010; 5:e10349. [PubMed: 20436965]

Gough JA, Murray NE. Sequence diversity among related genes for recognition of specific targets in DNA molecules. J Mol Biol. 1983; 166:1-19. [PubMed: 6304321]

Gould AD, Shilton BH. Studies of the maltose transport system reveal a mechanism for coupling ATP hydrolysis to substrate translocation without direct recognition of substrate. J Biol Chem. 2010; 285:11290-11296. [PubMed: 20147285]

Hall BG, Pikis A, Thompson J. Evolution and biochemistry of family 4 glycosidases: implications for assigning enzyme function in sequence annotations. Mol Biol Evol. 2009; 26:2487-2497. [PubMed: 19625389]

Harwood, CR.; Cutting, SM. Molecular biological methods for Bacillus. Chichester, England: John Wiley \& Sons; 1980.

Jacob AE, Hobbs SJ. Conjugal transfer of plasmid-borne multiple antibiotic resistance in Streptococcus faecalis var. zymogenes. J Bacteriol. 1974; 117:360-372. [PubMed: 4204433]

Law J, Buist G, Haandrikman A, Kok J, Venema G, Leenhouts K. A system to generate chromosomal mutations in Lactococcus lactis which allows fast analysis of targeted genes. J Bacteriol. 1995; 177:7011-7018. [PubMed: 8522504]

Le Breton Y, Pichereau V, Sauvageot N, Auffray Y, Rincé A. Maltose utilization in Enterococcus faecalis. J Appl Microbiol. 2005; 98:806-813. [PubMed: 15752325]

Lohmiller S, Hantke K, Patzer SI, Braun V. TonB-dependent maltose transport by Caulobacter crescentus. Microbiology. 2008; 154:1748-1754. [PubMed: 18524929]

Maguin E, Prévost H, Ehrlich SD, Gruss A. Efficient insertional mutagenesis in lactococci and other gram-positive bacteria. J Bacteriol. 1996; 178:931-935. [PubMed: 8550537]

Martin-Verstraete I, Deutscher J, Galinier A. Phosphorylation of HPr and Crh by HprK, early steps in the catabolite repression signalling pathway for the Bacillus subtilis levanase operon. J Bacteriol. 1999; 181:2966-2969. [PubMed: 10217795] 
Monedero V, Yebra MJ, Poncet S, Deutscher J. Maltose transport in Lactobacillus casei and its regulation by inducer exclusion. Res Microbiol. 2008; 159:94-102. [PubMed: 18096372]

Nallapareddy SR, Duh RW, Singh KV, Murray BE. Molecular typing of selected Enterococcus faecalis isolates: pilot study using multilocus sequence typing and pulsed-field gel electrophoresis. J Clin Microbiol. 2002; 40:868-876. [PubMed: 11880407]

Pikis A, Hess S, Arnold A, Erni B, Thompson J. Genetic requirements for growth of Escherichia coli K-12 on methyl-a-D-glucopyranoside and the five a-D-glucosyl-D-fructose isomers of sucrose. J Biol Chem. 2006; 281:17900-17908. [PubMed: 16636060]

Rajan SS, Yang X, Collart F, Yip VLY, Withers SG, Varrot A, Thompson J, Davies GJ, Anderson WF. Novel catalytic mechanism of glycoside hydrolysis based on the structure of an NAD ${ }^{+} / \mathrm{Mn}^{2+}$ dependent phospho-a-glucosidase from Bacillus subtilis. Structure. 2004; 12:1619-1629. [PubMed: 15341727]

Robrish SA, Fales HM, Gentry-Weeks C, Thompson J. Phosphoenol-pyruvate dependent maltose:phosphotransferase activity in Fusobacterium mortiferum ATCC 25557: Specificity, inducibility, and product analysis. J Bacteriol. 1994; 176:3250-3256. [PubMed: 8195080]

Rodríguez-Díaz J, Rubio-del-Campo A, Yebra MJ. Lactobacillus casei ferments the NAcetylglucosamine moiety of fucosyl-a-1,3-N-acetylglucosamine and excretes L-fucose. Appl Environ Microbiol. 2012; 78:4613-4619. [PubMed: 22544237]

Schönert S, Seitz S, Krafft H, Feuerbaum EA, Andernach I, Witz G, Dahl MK. Maltose and maltodextrin utilization by Bacillus subtilis. J Bacteriol. 2006; 188:3911-3922. [PubMed: 16707683]

Shelburne SA III, Keith DB, Davenport MT, Horstmann N, Brennan RG, Musser JM. Molecular characterization of group A Streptococcus maltodextrin catabolism and its role in pharyngitis. Mol Microbiol. 2008; 69:436-452. [PubMed: 18485073]

Spellerberg B, Rozdzinski E, Martin S, Weber-Heynemann J, Lütticken R. rgf encodes a novel twocomponent signal transduction system of Streptococcus agalactiae. Infect Immun. 2002; 70:24342440. [PubMed: 11953380]

Thompson J, Gentry-Weeks CR, Nguyen NY, Folk JE, Robrish SA. Purification from Fusobacterium mortiferum ATCC 2557 of a 6-phosphoryl-O-a-D-glucopyranosyl: 6-phosphoglucohydrolase that hydrolyzes maltose 6-phosphate and related phospho-a-D-glucosides. J Bacteriol. 1995; 177:2505-2512. [PubMed: 7730284]

Thompson J, Pikis A, Ruvinov SB, Henrissat B, Yamamoto H, Sekiguchi J. The gene glvA of Bacillus subtilis 168 encodes a metal-requiring, $\mathrm{NAD}(\mathrm{H})$-dependent 6-phospho-a-glucosidase. Assignment to family 4 of the glycosylhydrolase superfamily. J Biol Chem. 1998; 273:27347-27356. [PubMed: 9765262]

Thompson J, Lichtenthaler FW, Peters S, Pikis A. $\beta$-Glucoside kinase (BglK) from Klebsiella pneumoniae: Purification, properties, and preparative synthesis of 6 -phospho- $\beta$-D-glucosides. $\mathrm{J}$ Biol Chem. 2002; 277:34310-34321. [PubMed: 12110692]

Thompson J, Hess S, Pikis A. Genes malh and pagl of Clostridium acetobutylicum ATCC 824 encode $\mathrm{NAD}^{+}$- and $\mathrm{Mn}^{2+}$-dependent phospho-a-glucosidase(s). J Biol Chem. 2004; 279:1553-1561. [PubMed: 14570887]

Thompson J, Robrish SA, Pikis A, Brust A, Lichtenthaler FW. Phosphorylation and metabolism of sucrose and its five linkage-isomeric a-D-glucosyl-D-fructoses by Klebsiella pneumoniae. Carbohydr Res. 2001; 331:149-161. [PubMed: 11322729]

Vagner V, Dervyn E, Ehrlich SD. A vector for systematic gene inactivation in Bacillus subtilis. Microbiology. 1998; 144:3097-3104. [PubMed: 9846745]

Viana R, Monedero V, Dossonnet V, Vadeboncoeur C, Pérez-Martínez G, Deutscher J. Enzyme I and HPr from Lactobacillus casei: Their role in sugar transport, carbon catabolite repression and inducer exclusion. Mol Microbiol. 2000; 36:570-584. [PubMed: 10844647]

Webb AJ, Homer KA, Hosie AH. A phosphoenolpyruvate-dependent phosphotransferase system is the principal maltose transporter in Streptococcus mutans. J Bacteriol. 2007; 189:3322-3327. [PubMed: 17277067]

Weinrauch Y, Msadek T, Kunst F, Dubnau D. Sequence and properties of comQ a new competence regulatory gene of Bacillus subtilis. J Bacteriol. 1991; 173:5685-5693. [PubMed: 1715859] 
Woscholski R, Finan PM, Radley E, Totty NF, Sterling AE, Hsuan JJ, Waterfield MD, Parker PJ. Synaptojanin is the major constitutively active phosphatidylinositol-3,4,5-trisphosphate 5phosphatase in rodent brain. J Biol Chem. 1997; 272:9625-9628. [PubMed: 9092489]

Yamamoto H, Serizawa M, Thompson J, Sekiguchi J. Regulation of the glv operon in Bacillus subtilis: Yfia (GlvR) is a positive regulator of the operon that is repressed through CcpA and cre. $\mathrm{J}$ Bacteriol. 2001; 183:5110-5121. [PubMed: 11489864]

Yip VLY, Thompson J, Withers SG. Mechanism of GlvA from Bacillus subtilis: A detailed kinetic analysis of a 6-phospho-a-glucosidase from glycoside hydrolase family 4. Biochemistry. 2007; 46:9840-9852. [PubMed: 17676871] 


\section{Enterococcus faecalis}

Maltose operons



\section{Maltodextrin transport and amylase operons}

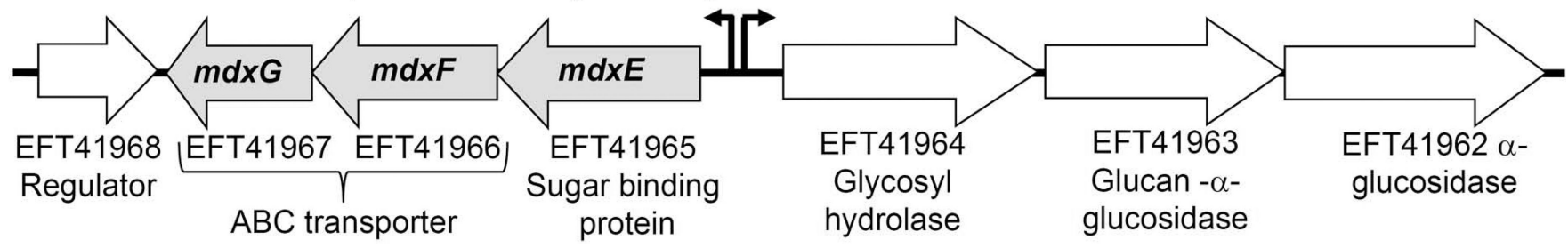

\section{Bacillus subtilis}
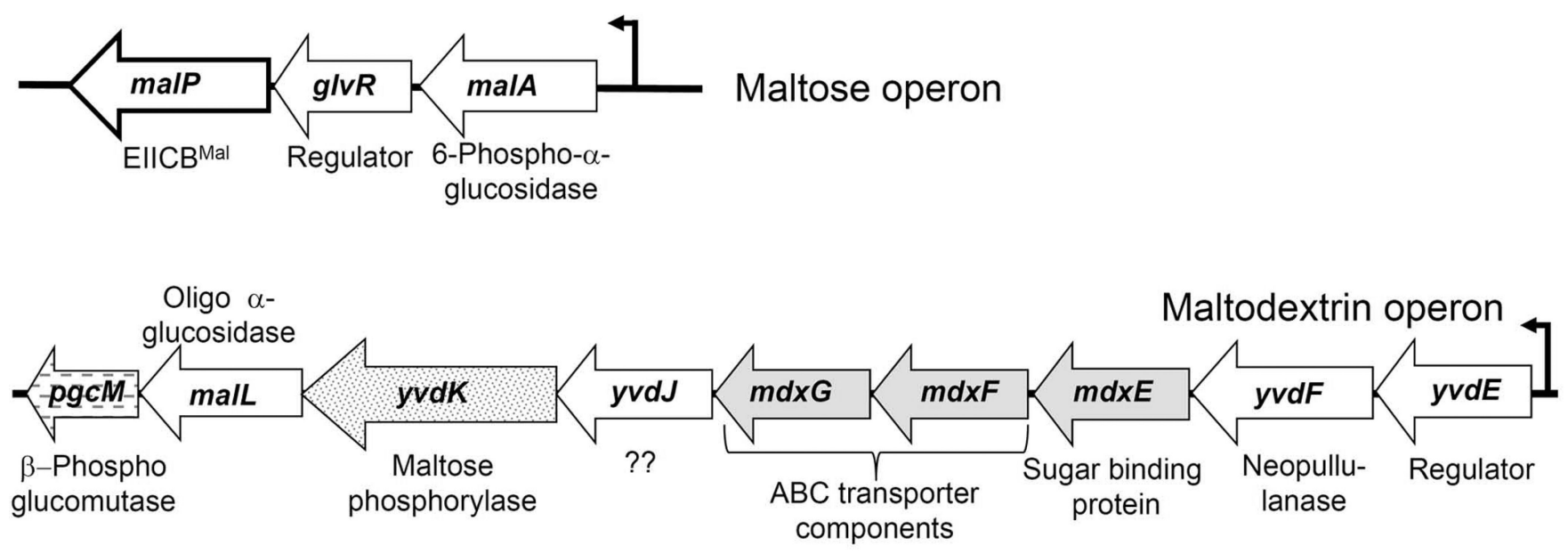

Fig. 1.

Comparison of the genes encoding the PTS and ABC transporter involved in maltose uptake in E. faecalis $\mathrm{JH} 2-2$ and $B$. subtilis 168. (A) In E. faecalis, the malP-pgcM-malMR operon contains the genes encoding a previously suggested maltose-6'-P phosphorylase (malP) (Le Breton et al., 2005), which we showed to function as maltose phosphorylase, a $\beta$ phosphoglucomutase ( $\operatorname{ggc} M)$, an aldose-1-epimerase (malM) and a transcriptional repressor ( $m a l R$ ). Oriented in the other direction are malT, which codes for a maltose-specific EIICBA of the PTS (Le Breton et al., 2005), and a gene encoding a protein of the endonuclease/exonuclease/phosphatase family of unknown function, which we identified as maltose-6'-P phosphatase (MapP). The operon encoding the ABC transporter for maltodextrins is located in a different place of the genome. Located upstream from the $m d x E F G$ operon (grey arrows) and oriented in the opposite direction are three genes encoding enzymes for the degradation of a-glucose polymers. (B) In $B$. subtilis, the malP gene encoding the EIICB ${ }^{\mathrm{Mal}}$ is associated with the malA gene, that encodes an $\mathrm{NAD}^{+} / \mathrm{Mn}^{2+}$ 
dependent P-a-glucosidase. The operon also includes the gene for a transcription regulator (Yamamoto et al., 2001). Similar to E. faecalis, the operon encoding the ABC transporter for maltodextrins (MdxEFG) is located in a different place of the genome. The $m d x E F G$ genes are preceded by two genes encoding a LacI-like repressor $(y v d E)$ and a maltogenic amylase $(y v d F)$ and followed by four genes encoding a protein of unknown function $(y v d J)$, a maltose phosphorylase $(y v d K)$, an oligo-a-glucosidase hydrolyzing longer maltodextrins (malL), and a phosphoglucomutase ( $p g c M)$. 

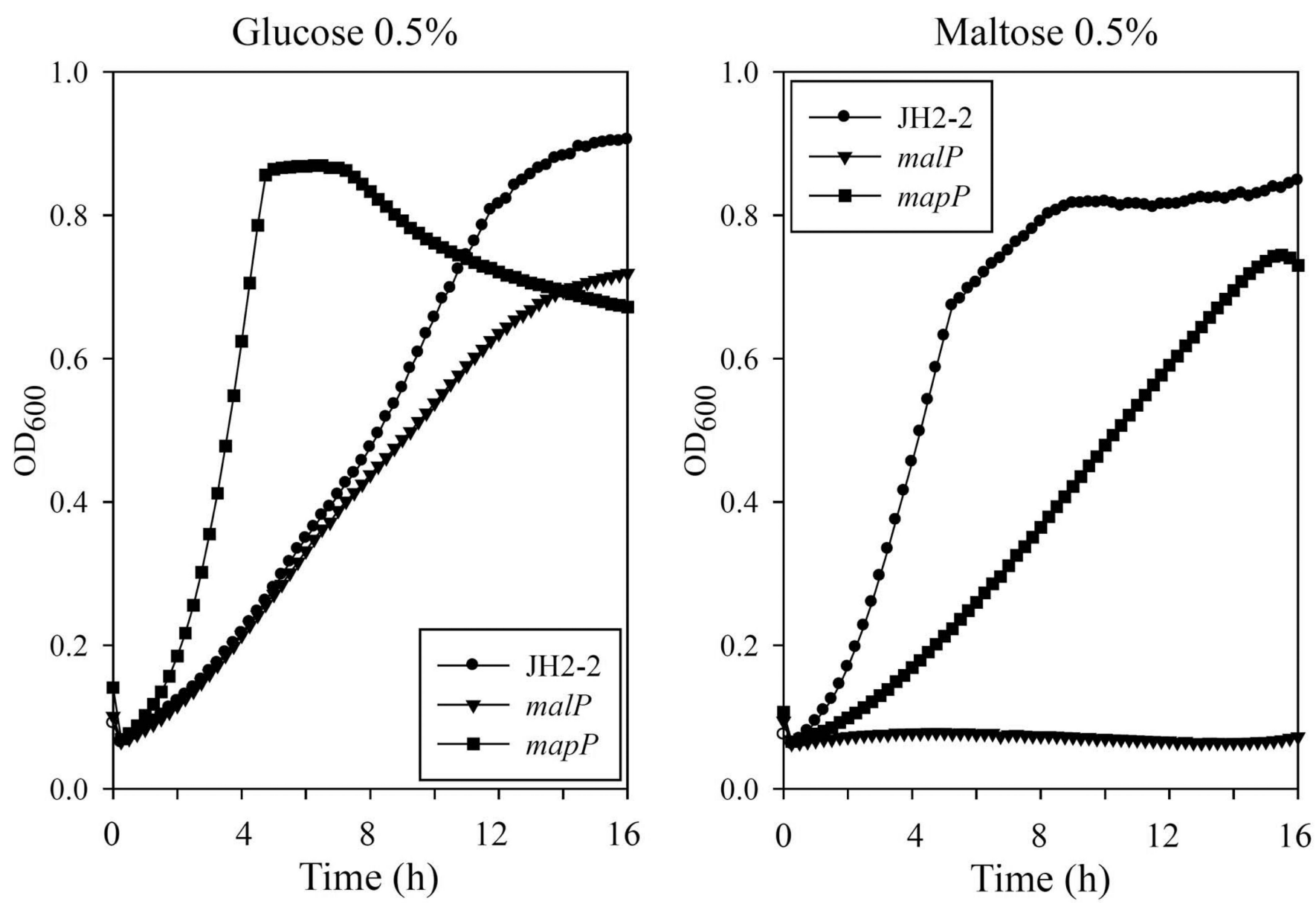

Fig. 2.

Growth behaviour of the $E$. faecalis wild-type strain $\mathrm{JH} 2-2$ and the malP and mapP mutants derived from it in carbon-depleted M17 medium complemented with (A) $0.5 \%$ glucose or (B) $0.5 \%$ maltose. Surprisingly, the mapP mutant grew faster on glucose-containing medium than the wild-type strain or the malP mutant. The latter had lost its capacity to grow on maltose-containing medium, whereas the mapP mutant exhibited only significantly reduced growth on maltose. The experiment was carried out three times and results identical to those presented here were always obtained. 


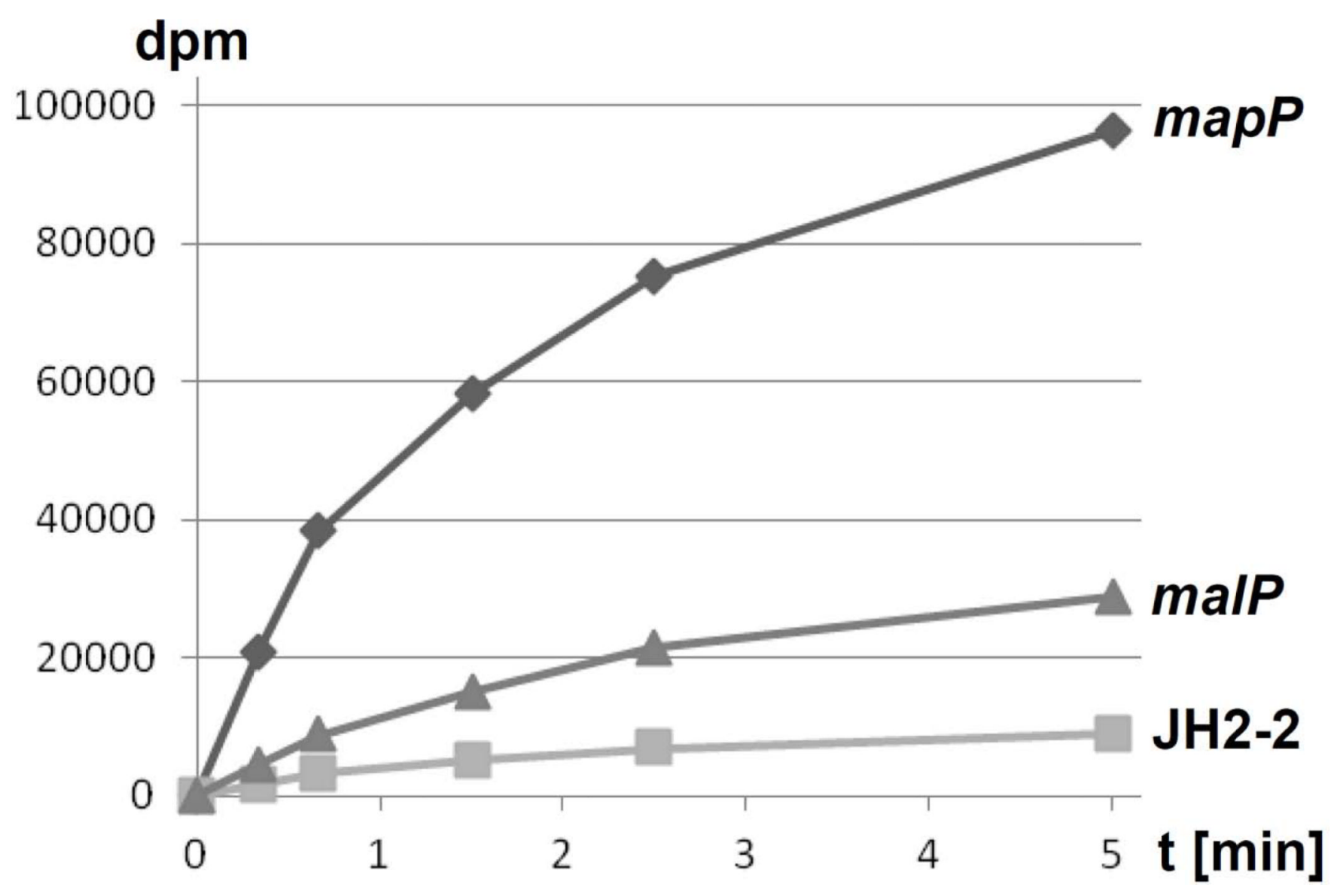

Fig. 3.

$\left[{ }^{14} \mathrm{C}\right]$-Maltose uptake studies with the $E$. faecalis wild-type strain $\mathrm{JH} 2-2$ (squares) and the malP(triangles) and mapP(diamonds) mutants derived from it. The experiments were carried out with $55 \mu \mathrm{M}\left[{ }^{14} \mathrm{C}\right]$-maltose as described in Experimental procedures. Aliquots of the assay mixture were withdrawn at $0.33,0.66,1.5,2.5$ and $5 \mathrm{~min}$ and filtered through 0.45 $\mu \mathrm{m}$ pore-size filters. The results presented in this figure are the mean values obtained from three independent experiments. The standard deviations did not exceed $15 \%$. 


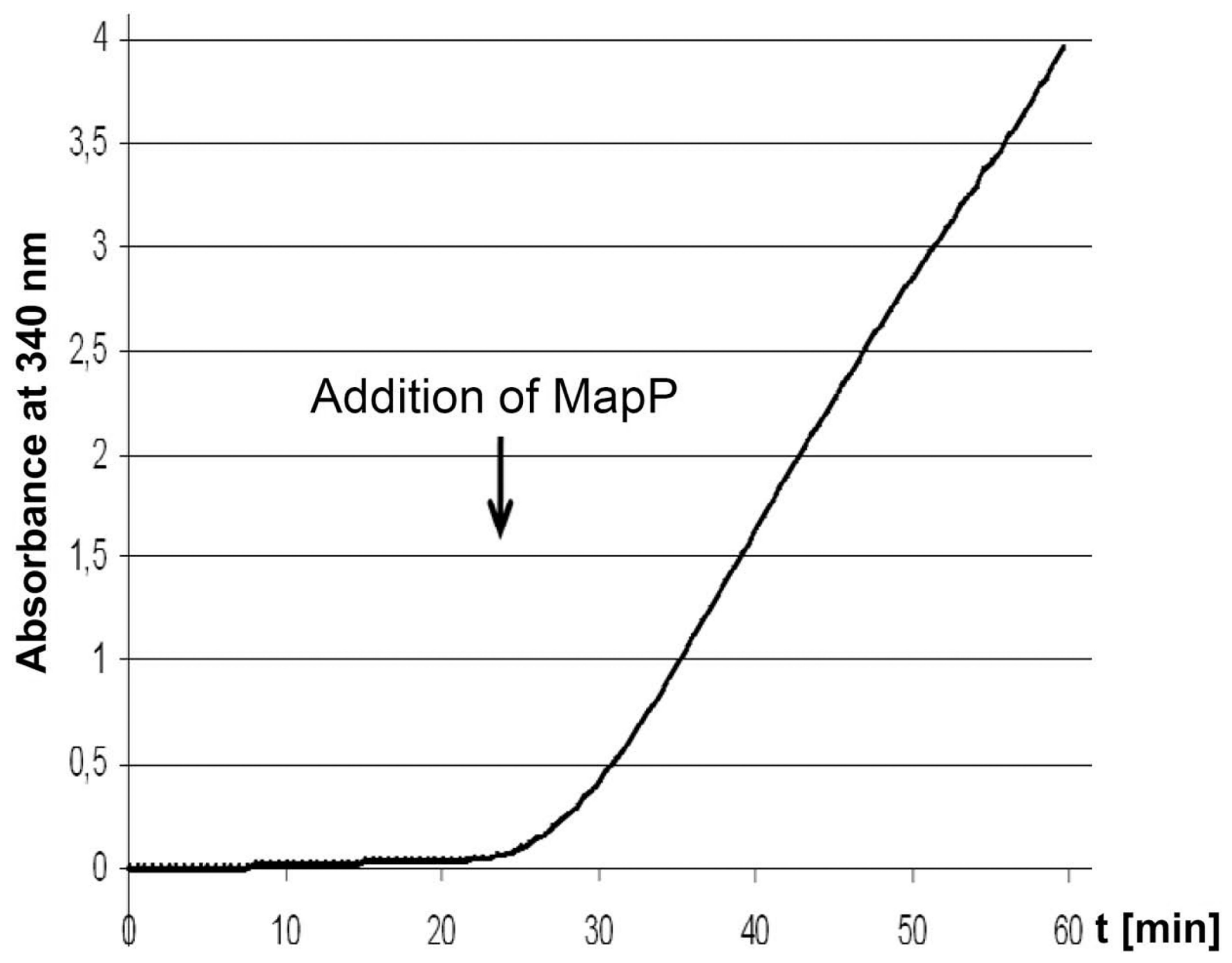

Fig. 4.

Coupled spectrophotometric assay of maltose-6'-P phosphatase activity. The reaction mixture contained $500 \mu \mathrm{l}$ glucose assay reagent, $500 \mu \mathrm{l} 50 \mathrm{mM}$ phosphate buffer, $\mathrm{pH} 7,10$ $\mathrm{mM} \mathrm{MgCl}_{2}, 1 \mathrm{mM}$ maltose-6'-P and $20 \mu \mathrm{l}$ maltose phosphorylase $\left(1.2 \mathrm{mg} \mathrm{ml}^{-1}\right)$. No formation of NADPH (increase of the absorbance at $340 \mathrm{~nm}$ ) was detected under these conditions. Only when the maltose-6'-P phosphatase (MapP) was added to the reaction mixture (arrow), was glucose produced from maltose-6'-P, and subsequently phosphorylated and oxidized to gluconate-6-P under NADPH formation. 




Mol Microbiol. Author manuscript; available in PMC 2014 April 01. 


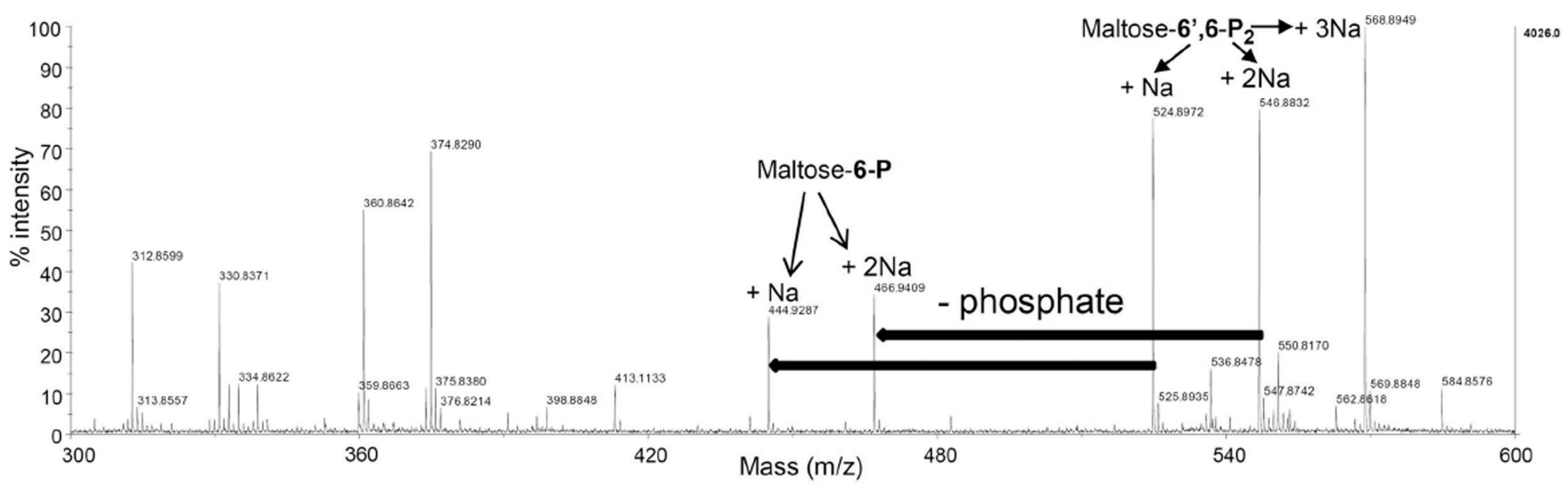

Fig. 5.

MapP-catalyzed dephosphorylation of (A and B) maltose-6'-P and (C and D) maltose-6',6$\mathrm{P}_{2}$ as evidenced by mass spectrometry. Dephosphorylation assays of maltose-6'-P or maltose-6',6- $\mathrm{P}_{2}$ with MapP and subsequent analysis by mass spectrometry were carried out as described in Experimental procedures. (A) Untreated maltose-6'-P: The two observed peaks at 445.09 and 467.07 correspond to maltose- 6 '-P with one $\left[(\mathrm{M}+\mathrm{H})+\mathrm{Na}^{+}\right]$or two $[(\mathrm{M}$ $\left.+\mathrm{H})+2 \mathrm{Na}^{+}\right] \mathrm{Na}^{+}$ions, respectively. (B) MapP-treated maltose-6'-P: These two peaks completely disappeared after treatment with MapP and a new single peak at 365.07 appeared, which corresponds to maltose carrying one $\mathrm{Na}^{+}$adduct. (C) Untreated maltose-6', 6- $\mathrm{P}_{2}$ : Owing probably to the additional phosphate group, maltose-6',6- $\mathrm{P}_{2}$ was able to bind up to three $\mathrm{Na}^{+}$ions and consequently three peaks at $524.95\left[(\mathrm{M}+\mathrm{H})+\mathrm{Na}^{+}\right], 546.94[(\mathrm{M}+\mathrm{H})$ $\left.+2 \mathrm{Na}^{+}\right]$and $568.94\left[(\mathrm{M}+\mathrm{H})+3 \mathrm{Na}^{+}\right]$were observed. (D) MapP-treated maltose-6',6-P $\mathrm{P}_{2}$ : These three peaks were still detected after treatment with MapP. Nevertheless, two small additional peaks appeared at 444.93 and 466.94 , which correspond to maltose-6-P carrying one $\left[(\mathrm{M}+\mathrm{H})+\mathrm{Na}^{+}\right]$or two $\left[(\mathrm{M}+\mathrm{H})+2 \mathrm{Na}^{+}\right] \mathrm{Na}^{+}$adducts, respectively. These results demonstrate that maltose- 6 ',6- $\mathrm{P}_{2}$ is a poor substrate for MapP and that only one of the two phosphate groups is removed by this enzyme. No peaks corresponding to maltose carrying one $\mathrm{Na}^{+}$adduct (365.07) appeared, which suggests that the enzyme specifically removes the phosphoryl group bound to the non-reducing sugar moiety in maltose-6',6- $\mathrm{P}_{2}$. Otherwise maltose-6'-P would have been formed, and (under the reaction conditions employed) should have been efficiently dephosphorylated to maltose (see, Fig. 5B). This was not the case. 


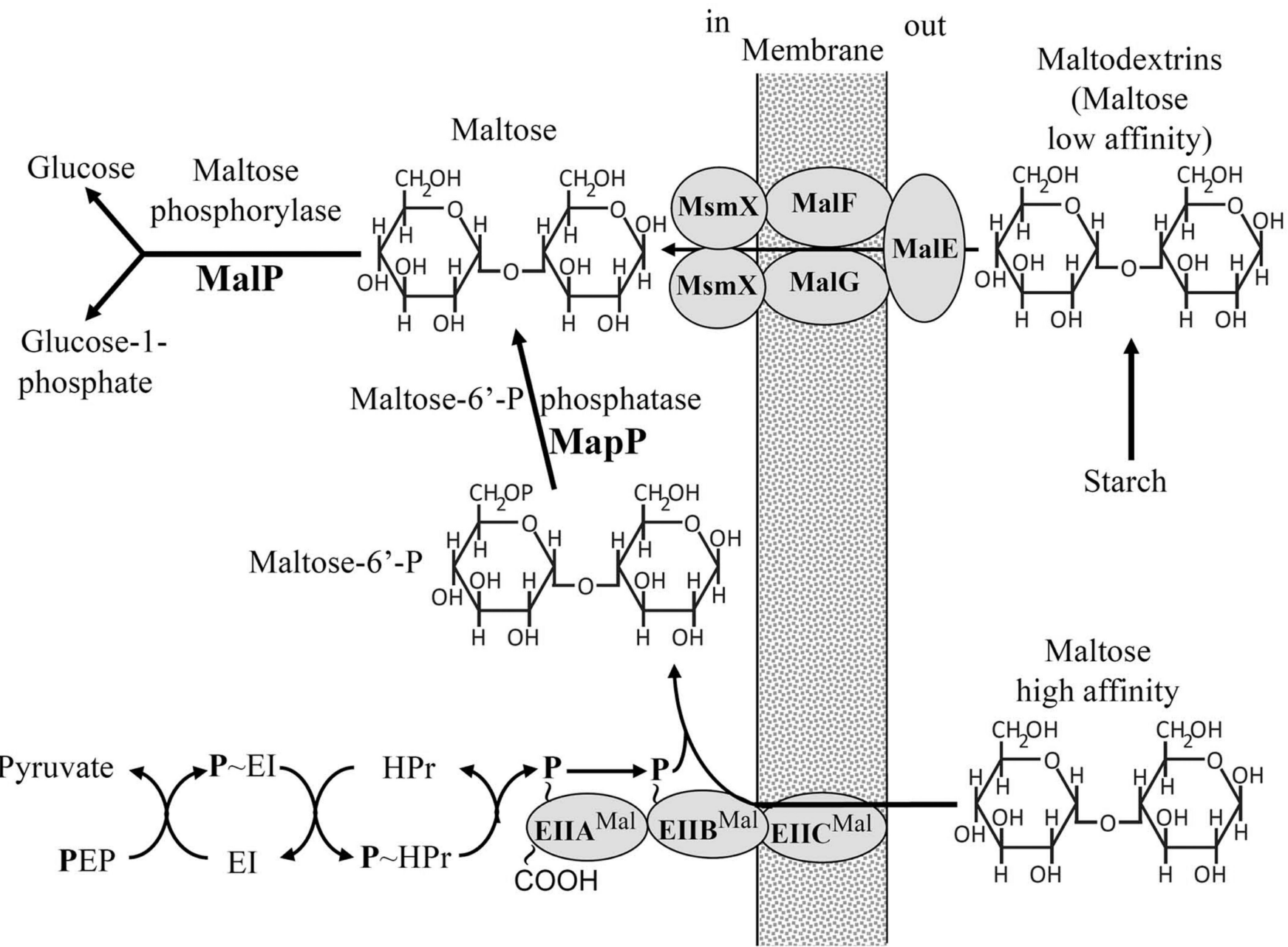

Fig. 6.

Proposed model for maltose uptake and metabolism in enterococci and other MalT- and MapP-containing bacteria. Maltose taken up by the low affinity ABC transport system is metabolized via the usual maltose phosphorylase-mediated pathway. Maltose taken up via the PTS enters the cells as maltose-6'-P. Enterococci and streptococci lack a 6-P-aglucosidase (MalA) which in other bacteria hydrolyzes maltose-6'-P into glucose and glucose-6-P. In contrast, enterococci and streptococci possess a phosphatase (MapP), which dephosphorylates intracellular maltose-6'-P to maltose, thereby connecting PTS-mediated maltose uptake to maltose phosphorylase-catalyzed metabolism. 


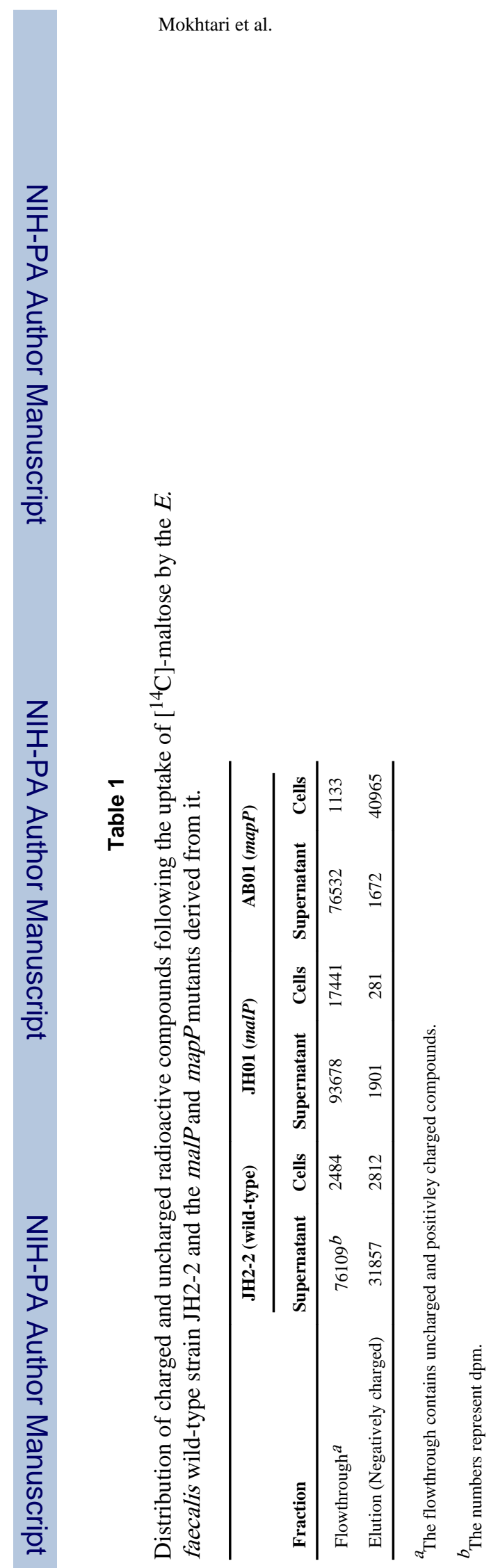

Mol Microbiol. Author manuscript; available in PMC 2014 April 01. 


\section{Table 2}

Dephosphorylation of phosphorylated sugars and sugar derivatives by the enzyme MapP. The formulae of the phosphorylated compounds are also presented.

\begin{tabular}{lccccc} 
Name & $\begin{array}{c}\text { Glycosidic } \\
\text { Linkage }\end{array}$ & $\begin{array}{c}\text { MapP } \\
\text { activity }^{a}\end{array}$ & $\begin{array}{c}\text { MapP } \\
\text { activity }^{b}\end{array}$ & $\begin{array}{c}\text { Formulae of phosphorylated } \\
\text { sugars }\end{array}$ \\
\hline Maltose-6'-P & $a(1 \rightarrow 4)$ & $(++)^{a}$ & 100 & &
\end{tabular}

Maltose-6',6- $\mathrm{P}_{2}$

Glucose-6-P

Fructose-6-P

Sucrose-6-P

Trehalulose- $\mathbf{6}^{\prime}-\mathbf{P}^{c}$ $a(1 \rightarrow 4)$

$\alpha / \beta$ equilibrium

$\alpha / \beta$ equilibrium

$(-)$

$a(1 \leftrightarrow 2) \beta$

$a(1 \rightarrow 1)$

$(-)$

$(-)$

( $)$
6.0



$(-)^{a}$

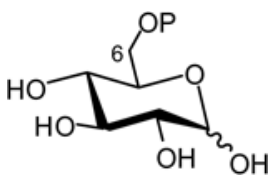

$(-)$



$(-)$

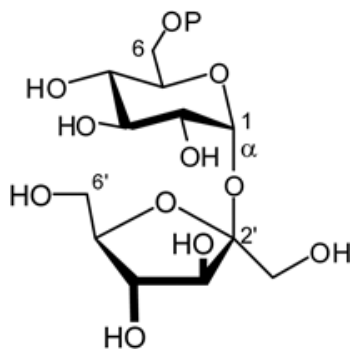

2.1 


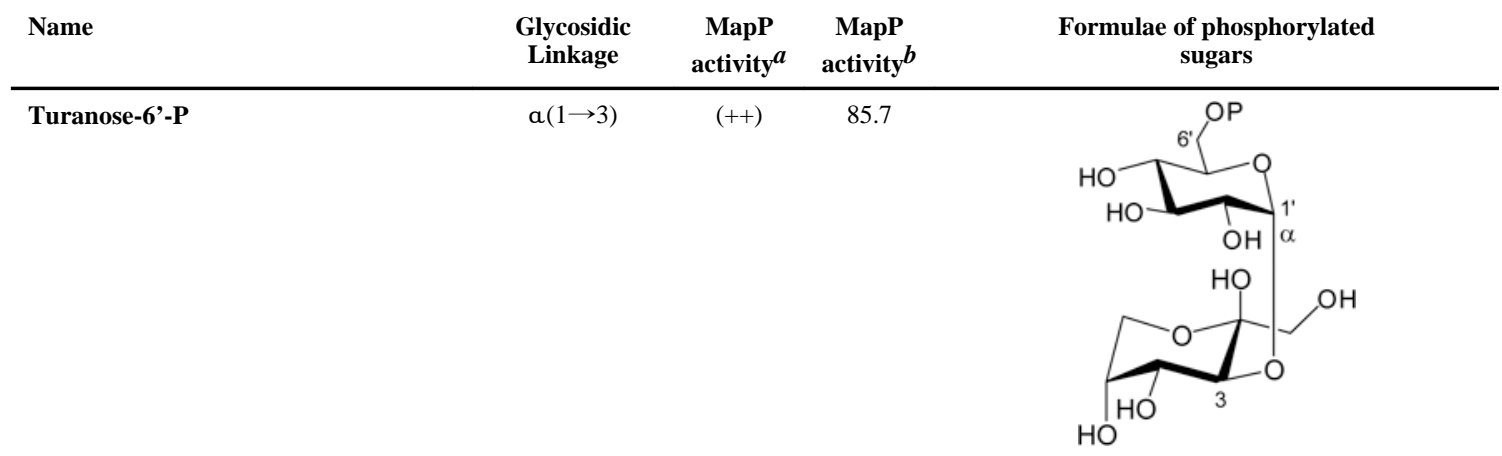

Maltulose-6'-P

$a(1 \rightarrow 4)$

$( \pm)$

8.1

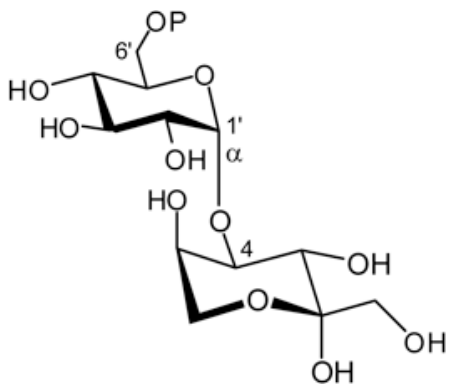

Leucrose-6'-P

$a(1 \rightarrow 5)$

$(++)$

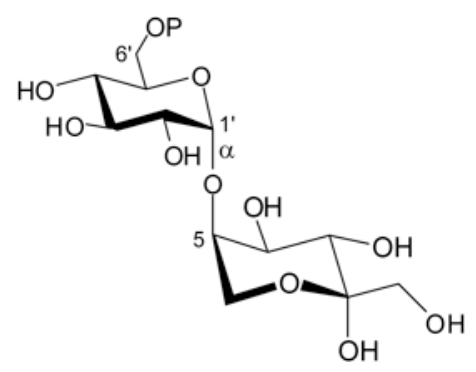

Palatinose-6'-P

$a(1 \rightarrow 6)$

$(+)$

18.8

Arbutin-6-P

$\beta$

$(-) \quad \quad \quad \mathrm{nd}^{d}$
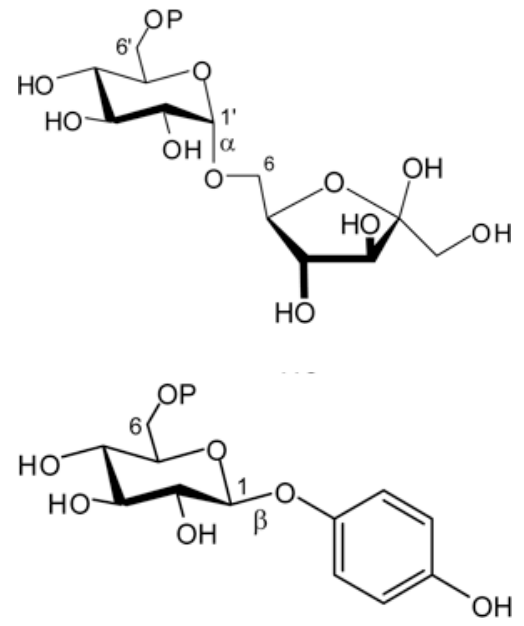


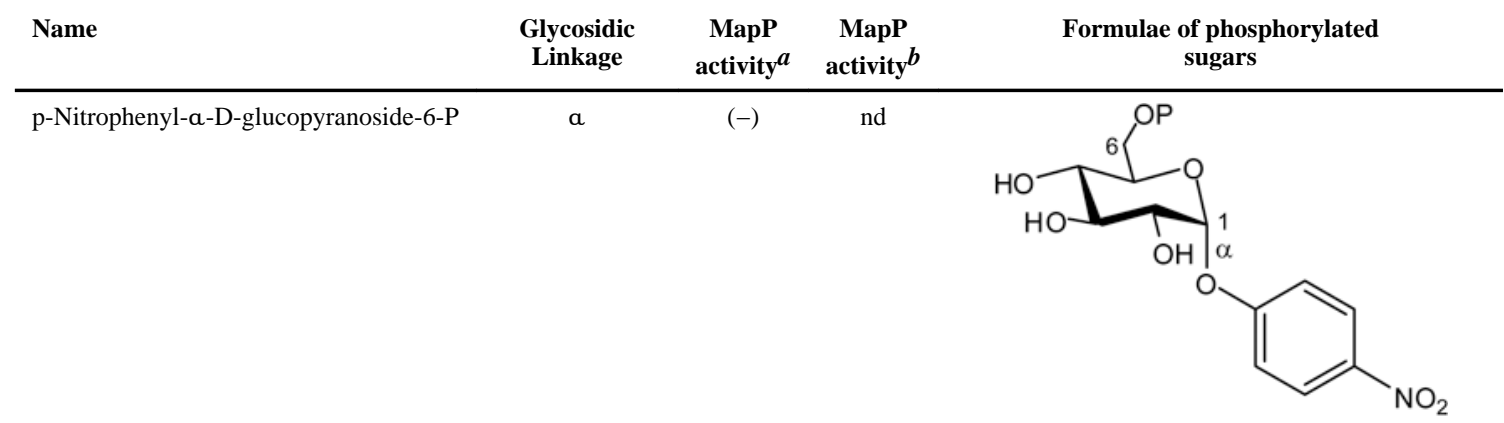

Esculin-6-P

Cellobiose-6'-P

Thiocellobiose-6'-P

Cellobiitol-6'-P

Gentiobiose-6'-P

$\beta$-methylglucoside-6-P $\beta$

$\beta(1 \rightarrow 4)$

$\beta(1 \rightarrow 4)$

$\beta(1 \rightarrow 4)$

$\beta(1 \rightarrow 6)$

$\beta$
(+)

0.6

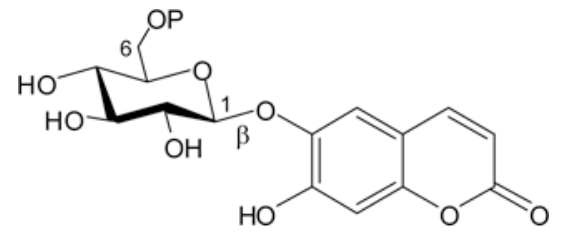

(-)

nd

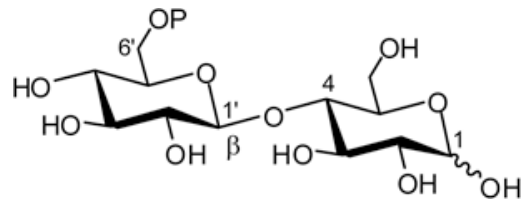

(-) nd



$(-)$

nd



$(-)$

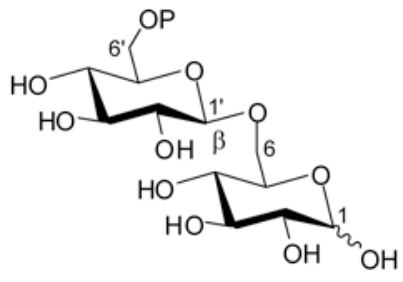

(-)






\begin{tabular}{lcccccc} 
Name & $\begin{array}{c}\text { Glycosidic } \\
\text { Linkage }\end{array}$ & $\begin{array}{c}\text { MapP } \\
\text { activity }\end{array}$ & $\begin{array}{c}\text { MapP } \\
\text { activity } b\end{array}$ \\
\hline Salicin-6-P & $\beta$ & $(-)$ & Formulae of phosphorylated \\
sugars
\end{tabular}

\footnotetext{
${ }^{a}$ MapP activity determined by mass spectrometry. $(++)=$ total dephosphorylation; $(+)=$ more than half dephosphorylated; $( \pm)=$ less than half dephosphorylated; $(-)=$ no detectable dephosphorylation.

${ }^{b}$ MapP activity determined with the malachite green phosphate assay. The activities determined with the different substrates are expressed relative to the activity measured with maltose-6'-P, which was set to $100 \%$.

$c^{c}$ The five $a$-linked isomers of sucrose-6-P are written in bold letters.

$d_{\text {nd stands for not determined. }}$
} 


\section{Table 3}

Effect of MapP treatment on the negatively charged radioactive compounds accumulated by the E. faecalis mapP mutant $\mathrm{AB} 01$. The experiment was carried out three times and in all cases comparable results were obtained.

\begin{tabular}{lcc}
\hline & Untreated & MapP-treated \\
\hline Uncharged Flowthrough $^{a}$ & $891^{b}$ & 34167 \\
Elution & 35334 & 2619 \\
\hline
\end{tabular}

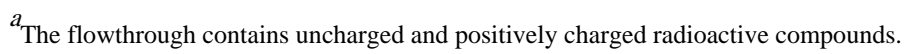

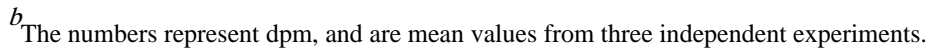


Table 4

Strains and plasmids used in this study

\begin{tabular}{|c|c|c|}
\hline Name of Stain & Relevant characteristics & Reference or source \\
\hline \multicolumn{3}{|l|}{ E. faecalis } \\
\hline JH2-2 (TX4000) & Fus $^{\mathrm{r}}$ Rif $^{\mathrm{T}}$; plasmid-free wild-type strain & (Jacob and Hobbs, 1974) \\
\hline JH-malP & JH2-2 with pGhost8::malP insertion & This study \\
\hline $\mathrm{AB} 01$ & JH2-2 with pUCB30bis::mapP insertion & This study \\
\hline \multicolumn{3}{|l|}{ B. subtilis } \\
\hline 168 & $\operatorname{trp} C 2$ & Laboratory stock \\
\hline AM01 & 168 malA deletion mutant & This study \\
\hline AM02 & AM01 mdx $G:$ :pMUTIN-I & This study \\
\hline \multicolumn{3}{|l|}{ E. coli } \\
\hline NM522 & $\begin{array}{l}\text { supE thi-1 } \Delta(\text { lac-proAB }) \Delta(\text { mcrB-hsdSM })\left(\mathrm{r}_{\mathrm{k}^{-}} \mathrm{m}_{\mathrm{k}^{-}}\right)\left[\mathrm{F}^{\prime} \text { proAB laclq } Z \Delta \mathrm{GM} 15\right] \text {; expression } \\
\text { of His-tagged proteins }\end{array}$ & (Gough and Murray, 1983) \\
\hline EC101 & $\begin{array}{l}\left.\text { Kan }{ }^{\mathrm{r}} \operatorname{supE} \text { thi (lacproAB) (F' traD36 proAB lac/ } \mathrm{Z} \Delta \mathrm{M} 15\right) \text { repA, used as host for pGhost8 } \\
\text { constructs }\end{array}$ & (Law et al., 1995) \\
\hline \multicolumn{3}{|l|}{ Plasmids } \\
\hline pGhost8 & Thermosensitive replication origin, $\left(\mathrm{Tet}^{\mathrm{R}}\right)$ & (Maguin et al., 1996) \\
\hline pGh-malP & pGhost8 carrying an internal 594 bp fragment of malP & This study \\
\hline pUCB30bis & E. faecalis suicide vector & (Benachour et al., 2007) \\
\hline pUCB30bis-mapP & pUCB30bis carrying an internal $450 \mathrm{bp}$ fragment of mapP & This study \\
\hline pUC18 & Cloning vector & \\
\hline pAC7 & B. subtilis integration vector at the amyE site & (Weinrauch et al., 1991) \\
\hline pAC7-PptsH & pAC7 carrying the $B$. subtilis pts $H$ promoter and SD box & This study \\
\hline pAC7-PptsH-mapP & mapP gene expressed from the $B$. subtilis pts $H$ promoter & This study \\
\hline pMUTIN4 & $\begin{array}{l}\text { B. subtilis gene inactivation vector carrying lacI and Pspac for inducible transcription of } \\
\text { downstram genes }\end{array}$ & (Vagner et al., 1998) \\
\hline pMUTIN-mdxG & pMUTIN4 carrying an internal 494 bp fragment of $B$. subtilis $m d x G$ & This study \\
\hline pMAD & Thermosensitive replication origin, $\left(\mathrm{Erm}^{\mathrm{R}}\right)$ & (Arnaud et al., 2004) \\
\hline pMAD-malA & pMAD carrying $B$. subtilis malA with an internal deletion & This study \\
\hline pQE30 & His-tag expression vector & Qiagen \\
\hline pQE30-malP & His-tagged maltose phosphorylase & This study \\
\hline pQE30-mapP & His-tagged maltose-6'-P phosphatase & This study \\
\hline
\end{tabular}


Table 5

Oligonucleotides used in this study

\begin{tabular}{lll} 
Name & Sequence & Restriction site \\
\hline EfMalP_Up & AAAGGATCCATGAAACAAATCAAAC & BamHI \\
EfMallP_Lo & AGGGGTACCTTAAACATGAACTTCTTC & KpnI \\
Ef0960BamF & GGGGGATCCATGAATCTTTTAACAATCAATAC & BamHI \\
Ef0960SalR & GCGCGTCGACTTATTTTAGTTGAATGAGTAAGCC & SalI \\
mapPForBam & GGGGGATCCATGAATCTTTTAACAATCAATACTC & BamHI \\
mapPRevSac & TGAGAGCTCAGCGCTTTTTCTTATTTTAGTTGAATGAG & SacI \\
EfMalPmut_U & CATAAGCTTTCGCACCATTTCTGTG & HindIII \\
EfMalPmut_L & GGGAATTCTGTTGTGCCTACATATACAC & EcoRI \\
VerifMalP & CCCCATCTAAATCAAACAAAACG & - \\
MapPBamF & AGAGGATCCATTAAAAAAATTAGAGGAG & BamHI \\
MapPEcoR & TAGGAATTCATAGGCAAAACCTGTACAG & EcoRI \\
EFmapPconf & CCGATAGTCAGTGATCATTTTGGC & - \\
PU & TGTAAAACGACGGCCAGT & - \\
PR & CAGGAAACAGCTATGACC & - \\
malAIForBam & AGTGGATCCAGTGACTACATCATTTGCAAGC & BamHI \\
malA1RevKpn & CTGAGGTACCAGTTCTTCGAGCTGCATATCAGATC & KpnI \\
VerifMalAFor & GGGATCGAAGACCGGATGGCGC & - \\
VerifMalARev & GGCCAGCGCGTCGATTCCAAGG & - \\
mdxGForHind & CATCAAGCTTCCGTGTGGGGAATTCGGCG & HindIII \\
mdxGRevBam & ATAAGGATCCAAAGCGCTTGTACCGCGAGC & BamHI \\
ptsHPromForEco & GAGGAATTCAAGATATTGTGAAGATTGAAA & EcoRI \\
ptsHPromRevBam & CATGGATCCCATTCTCCTTTTAACTTAAAG & BamHI \\
\hline & &
\end{tabular}

